\title{
Evidence of Bulk Proton Insertion in Nanostructured Anatase and Amorphous $\mathrm{TiO}_{2}$ electrodes
}

\author{
Nikolina Makivić, ${ }^{\dagger}$ Jae-Young Cho, ${ }^{\ddagger}$ Kenneth D. Harris, ${ }^{\ddagger}, \#$ Jean-Marie Tarascon, ${ }^{\S}$ Benoît Li- \\ moges, ${ }^{*} \dagger$ Véronique Balland ${ }^{*, \dagger}$ \\ †Laboratoire d'Electrochimie Moléculaire, Université de Paris, UMR CNRS 7591, 15 rue Jean-Antoine de Baïf, 75013 \\ Paris, France \\ ${ }^{\ddagger}$ National Research Council of Canada, Nanotechnology Research Centre, 11421 Saskatchewan Drive, Edmonton, \\ Alberta T6G 2M9, Canada \\ \#Department of Mechanical Engineering, University of Alberta, Edmonton, Alberta $\mathrm{T}_{6 \mathrm{G}} 2 \mathrm{~V}_{4}$, Canada \\ ${ }^{\S}$ Chimie du Solide et de l'Energie, UMR 826o, Collège de France, 11 Place Marcelin Berthelot, 75231 Paris Cedex o5, \\ France
}

KEYWORDS. Aqueous battery, proton-coupled electron transfer, proton intercalation, phase transition, metal oxide.

\begin{abstract}
Crystalline structures and lattice water molecules are believed to strongly influence the ability of metal oxides to reversibly and rapidly insert protons in aqueous batteries. In the present work, we performed a systematic analysis of the electrochemical charge storage properties of nanostructured $\mathrm{TiO}_{2}$ electrodes composed of either anatase or amorphous $\mathrm{TiO}_{2}$ in a mild buffered aqueous electrolyte. We demonstrate that both materials allow reversible bulk proton insertion up to a maximal reversible gravimetric capacity of $\sim 150 \mathrm{~mA} \cdot \mathrm{h} \cdot \mathrm{g}^{-1}$. We also show that the $\mathrm{TiO}_{2}$ crystallinity governs the energetics of the charge storage process, with a phase transition for anatase, while having little effect on either the interfacial charge-transfer kinetics or the apparent rate of proton diffusivity within the metal oxide. Finally, with both $\mathrm{TiO}_{2}$ electrodes, reversible proton insertion leads to gravimetric capacities as high as $95 \mathrm{~mA} \cdot \mathrm{h} \cdot \mathrm{g}^{-1}$ at $75 \mathrm{C}$. We also reveal two competitive reactions decreasing the Coulombic efficiency at low rates, i.e. hydrogen evolution and a nonfaradaic self-discharge reaction. Overall, this work provides a comprehensive overview of the proton-coupled electrochemical reactivity of $\mathrm{TiO}_{2}$ and highlights the key issues to be solved in order to truly benefit from the unique properties of protons as fast charge carriers in metal oxides.
\end{abstract}

\section{INTRODUCTION}

Rechargeable batteries meeting economic and ecological sustainability criteria are highly desirable, especially when the aim is to contribute to the development of large scale energy storage for both individual and grid applications., Therefore, over the last decade, tremendous efforts have been made to study a wide range of earth-abundant insertion electrode materials (many of them based on metal oxides) able to operate in aqueous electrolytes with different monovalent $\left(\mathrm{Li}^{+}, \mathrm{K}^{+}, \mathrm{Na}^{+}\right)$or multivalent $\left(\mathrm{Zn}^{2+}, \mathrm{Mg}^{2+}, \mathrm{Al}^{3+}, \ldots\right)$ insertion cations. 3 In contrast, much less attention has been paid to systems involving the proton as an insertion cation, which is surprising because the small size and ubiquity of protons make them very well suited for the development of sustainable batteries with high rate capabilities and cycling stabilities. $^{2}$ These attractive attributes are all the more interesting if one considers the recent finding that protons can reversibly insert into a metal oxide from a neutral or slightly acidic aqueous electrolyte containing a weak Brønsted acid.4,5 This finding offers the opportunity to develop aqueous batteries that are both safer and more durable by avoiding the highly corrosive conditions (i.e., strongly acidic or basic conditions) commonly encountered with aqueous proton-based batteries. ${ }^{6}$ The use of buffered aqueous electrolytes was indeed proven to be a relevant strategy to stabilize the $\mathrm{pH}$ at metal oxide interfaces, which is key to yielding aqueous batteries with highly stable charge/discharge voltages. 7 This concept of proton insertion via a weak acid also applies to multivalent aquo-metal complexes (e.g., $\left.\left[\mathrm{Zn}\left(\mathrm{H}_{2} \mathrm{O}\right)_{6}\right]^{2+}, \quad\left[\mathrm{Al}\left(\mathrm{H}_{2} \mathrm{O}\right)_{6}\right]^{3+}, \ldots\right)$, which generally possess an intrinsic weak acidity through their coordinated water molecules.,5-10

To date, most of the knowledge on the bulk insertion of protons in metal oxides comes from studies on nickel hydroxide materials. This is mainly because they are abundantly used as cathodic active materials in alkaline 
nickel-metal hydride (NiMH) or nickel-zinc aqueous batteries. ${ }^{11}$ It is only recently that a broader interest in the reversible insertion of protons in various metal oxides has emerged.12 So far, the majority of materials examined for their reversible proton insertion properties are hydrated transition metal oxides (mostly layered) such as $\mathrm{WO}_{3} \cdot \mathrm{nH}_{2} \mathrm{O},{ }^{13-15} \quad \mathrm{H}_{2} \mathrm{~W}_{2} \mathrm{O}_{7},{ }^{16} \quad \mathrm{MoO}_{3}{ }^{17-19} \quad \mathrm{H}_{x} \mathrm{IrO}_{4}{ }^{20,21} \quad \mathrm{VO}_{2}{ }^{8,22}$ $\mathrm{V}_{2} \mathrm{O}_{5},{ }^{9}$ and $\mathrm{H}$-titanates. ${ }^{23,24}$ In many of these studies, it has been proposed that the presence of ions and/or structural water in the interlayer space or in the tunnel structure of the metal oxide material facilitates the transport of protons within the solid phase.

Among the transition metal oxides that have been investigated for their proton storage capabilities, $\mathrm{TiO}_{2}$ and its polymorphs are quite attractive because of their low cost, earth abundance, nontoxicity, and chemical stability in aqueous media over a wide range of $\mathrm{pHs}$. Moreover, the oneelectron reduction potential of $\mathrm{TiO}_{2}\left(\mathrm{Ti}^{\mathrm{IV}} / \mathrm{Ti}^{\mathrm{III}}\right)$ is quite low and, considering that one-electron is stored per Ti redoxactive center, this leads to a theoretical gravimetric capacity as high as $335 \mathrm{~mA} \cdot \mathrm{h} \cdot \mathrm{g}^{-1}, 25$ making $\mathrm{TiO}_{2}$ a good anode candidate for the development of rechargeable proton-based batteries. Another interesting aspect of $\mathrm{TiO}_{2}$-based electrodes is that they were widely investigated for their ability to reversibly insert $\mathrm{Li}^{+}$ions from organic electrolytes. These $\mathrm{Li}^{+}$studies can therefore be used for comparison with proton insertion. For example, it was notably shown that the stoichiometry of the reduced $\mathrm{Li}_{x} \mathrm{TiO}_{2}$ phase can vary with the morphology and/or degree of crystallinity (ranging from $x=$ 0.5 for bulk anatase to $x=1$ for $\left.\mathrm{TiO}_{2}(\mathrm{~B})\right) .{ }^{26-29}$ Concerning the insertion of protons in $\mathrm{TiO}_{2}$-based materials, the question of stoichiometry remains open. Proton uptake during the reductive electrochemical doping of anatase was originally revealed by EQCM,30 accounting for the $-60 \mathrm{mV} / \mathrm{pH}$ unit dependence of the flatband potential.31 It was thereafter revealed that proton insertion in titanium oxides is restricted to a near-surface region, 32,33 thereby limiting their relevance as proton charge storage materials. It is only recently that layered titanates were proposed for bulk electrochemical $\mathrm{H}^{+}$ intercalation, with the underlying assumption that water molecules or structural protons in the interlayer space facilitate the bulk insertion of protons.23,24 This contrasting view between layered and nonlayered titanate materials is however challenged by the relatively high proton charge storage gravimetric capacity of $118 \mathrm{~mA} \cdot \mathrm{h} \cdot \mathrm{g}^{-1}$ (equivalent to $x=$ o.35) we have recently obtained for a nonlayered amorphous $\mathrm{TiO}_{2}$ electrode immersed in a buffered aqueous electrolyte. ${ }^{5}$ These conflicting results raise fundamental questions about the structural features that a metal oxide phase has to meet in order to allow for a fast and reversible bulk proton insertion.

In the present study, we aim to resolve these open questions concerning proton insertion in $\mathrm{TiO}_{2}$, through a comparative study of crystalline (anatase) and amorphous $\mathrm{TiO}_{2}$ electrodes. For such purpose, we have chosen to work with model electrodes based on nanostructured $\mathrm{TiO}_{2}$ thin films deposited in a one-step glancing angle deposition (GLAD) process onto flat Ti-coated glass substrates. 5 This deposition method has the merit of offering accurate control over the shape and morphology of the deposited nanostructured $\mathrm{TiO}_{2}$ film, thereby leading to the production of highly reproducible mesoporous electrodes with a high aspect ratio (i.e., nanocolumn arrays extending perpendicularly from the current collector).34 These pure material mesoporous electrodes also have the advantage of avoiding side effects arising from complex composite electrode materials classically used in batteries (i.e. mixtures made of carbon powder, active material, and polymeric binder). On account of their well-defined and well-controlled porosity as well as good adhesion to the conductive Ti-coated glass substrate, these mesoporous GLAD $\mathrm{TiO}_{2}$ electrodes also showed an efficient mass transport of the electrolyte through their pore structures, as well as a fairly good electrical connectivity across the entire film thickness. 5 Furthermore, the anatase crystalline phase can be easily obtained by thermal annealing of the as-deposited amorphous $\mathrm{GLAD} \mathrm{TiO}_{2}$ film, ensuring an identical mass of active material for both amorphous and anatase electrodes, which is very useful for a comparative study. These model electrodes are thus well suited for quantitative analysis of the proton insertion-coupled electron transfer reaction in both anatase and amorphous $\mathrm{TiO}_{2}$ phases.

\section{EXPERIMENTAL SECTION}

Chemicals. Acetic acid (Reagent plus, >99\%), sodium acetate, $\mathrm{KCl}$ (GR for analysis), and ethanol absolute (EMSURE) were purchased from Sigma-Aldrich/Merck. Acetonitrile (99.9\% Acroseal $^{\circledR}$ ) was purchased from Acros Organics. $\mathrm{LiClO}_{4}(>98 \%)$ was purchased from Fluka and stored in a glove box. Acetone (Normapur) was purchased from VWR Chemicals, and 1-propanol from Alfa Aesar. Nafion D-520 dispersion was purchased from Alfa Aesar. All aqueous solutions were made with Milli- $\mathrm{Q}^{\circledR}$ water (18.2 $\mathrm{M} \Omega \cdot \mathrm{cm})$.

Mesoporous GLAD-TiO ${ }_{2}$ electrodes. Nanostructured electrodes were prepared by physical vapor deposition of a mesoporous amorphous $\mathrm{TiO}_{2}$ film under glancing angle deposition (GLAD) as previously published.5 Clean glass substrates were first coated with a dense $250 \mathrm{~nm}$-thick layer of $\mathrm{Ti}$ using a deposition angle of $5^{\circ}$. GLAD- $\mathrm{TiO}_{2}$ deposition followed at a fixed oblique angle of $72^{\circ}$ while continuously rotating the substrate at a rate of one complete rotation for every $10 \mathrm{~nm}$ of $\mathrm{TiO}_{2}$ film growth until the mesoporous $\mathrm{TiO}_{2}$ film was $1 \mu \mathrm{m}$ thick. The resulting amorphous GLAD-TiO electrodes were used without further processing steps. Anatase GLAD- $\mathrm{TiO}_{2}$ electrodes were prepared by heating amorphous electrodes under air in a Carbolite CWF 1200 oven. The heating rate was $5^{\circ} \mathrm{C} / \mathrm{min}$, the peak temperature was $400^{\circ} \mathrm{C}$, and the electrodes were held for $2 \mathrm{~h}$ before removal.

Electrode cleaning and modification. Prior to use, electrodes were cleaned in an ultraviolet ozone cleaner (UV/O $\mathrm{O}_{3}$ Procleaner ${ }^{\mathrm{TM}}$ plus, Bioforce Nanosciences) for $15 \mathrm{~min}$ and subsequently soaked at room temperature in acetone and then ethanol for 15 and $30 \mathrm{~min}$, respectively. The electroactive GLAD- $\mathrm{TiO}_{2}$ surface was delimited by depositing nail vanish to define a rectangular geometric electrode area $S$ of $0.56 \mathrm{~cm}^{2}$. For Nafion ${ }^{\mathrm{TM}}$ coating, a Nafion ${ }^{\mathrm{TM}} \mathrm{D}-520$ dispersion, $5 \% \mathrm{w} / \mathrm{w}$ in water and 1-propanol, was diluted with a 1:1 mixture of water and ethanol in a 1:3 volume ratio. $20 \mu \mathrm{L}$ 
of this mixture was drop-casted on the working electrode surface and then left to dry for $30 \mathrm{~min}$ at room temperature and under ambient air.

Structural characterization. X-ray powder diffraction (XRD) measurements were carried out with a Bruker model D8/Discover X-ray diffractometer using a filtered $\mathrm{Cu} \mathrm{K \alpha}$ radiation source $(\lambda=1.54178 \AA$ ) $)$. The $2 \theta$ range for each sample was from $20^{\circ}$ to $50^{\circ}$ with a step size of $\mathbf{0 . 0 2}^{\circ}$. The collected data was carefully analyzed using EVA $^{\text {tm }}$ software.

Scanning electron microscopy (SEM) and transmission electron microscopy (TEM) were used to investigate the morphology of the GLAD electrodes and the size of $\mathrm{TiO}_{2}$ crystallites. For SEM imaging, an ultra-high resolution Hitachi S-550o cold field emission SEM was used with a $30 \mathrm{kV}$ accelerating voltage and $30 \mu \mathrm{A}$ emission current. For ex situ TEM analysis, a Hitachi HT770o TEM equipped with a W electron source was used at $100 \mathrm{kV}$. In order to study the anatase crystallite formation, in situ TEM investigation was performed with a Hitachi H950o environmental TEM (ETEM) equipped with a variable-temperature gas-injection holder. Both SEM and TEM samples were prepared by scraping the GLAD film from the Ti/glass substrate and transferring to holey carbon-coated 400-mesh copper grids (Electron Microscopy Sciences). Atomic force microscopy (AFM) was performed using a Veeco Instruments MultiMode Nanoscope IV AFM equipped with an E scanner. To obtain a clear image from the surface, high resolution, soft tapping mode AFM probes (MikroMasch USA, Inc.) with low spring constants of $5.0 \mathrm{~N} / \mathrm{m}$ and $1 \mathrm{~nm}$ radius were used. The area fractions of gaps between posts were determined by image analysis using ImageJ software. To examine internal structural changes within the GLAD- $\mathrm{TiO}_{2}$ electrodes after galvanostatic cycling, a focussed ion beam (FIB) process was perfomed using a Zeiss NVision 40. This tool is a dual-beam instrument combining a Schottky field emission SEM for imaging with a focused beam of gallium ions to remove sections of the film. To protect the film surfaces and avoid charging issues, the samples were pre-coated with a $200 \mathrm{~nm}$ thick layer of Au-Pd using a Gatan precision sputtering system. Ion milling was performed with a $30 \mathrm{kV}$ gallium ion beam operating with a beam current of $80 \mathrm{pA}$.

Electrochemical characterization. Cyclic voltammetry and galvanostatic cycling experiments were performed in a standard three electrode cell configuration using a BioLogic VSP potentiostat controlled by the EC-Lab software. The counter electrode was a platinum wire, and the reference electrode was a saturated calomel electrode (SCE). The aqueous electrolyte was either $1 \mathrm{M}$ acetate buffer at $\mathrm{pH}$ 5.0, or $0.5 \mathrm{M} \mathrm{KCl}$ stabilized at $\mathrm{pH} 5$ by addition of $\mathrm{HCl}$. The organic electrolyte was $1 \mathrm{M} \mathrm{LiClO}_{4}$ in dry acetonitrile. Prior to measurements, the electrolyte was carefully degassed for $20 \mathrm{~min}$, and a constant argon flow was maintained above the electrochemical cell during the entire experiment. In CV experiments, a systematic Ohmic drop compensation was performed. The current density was calculated from the current intensity normalized to the electrode geometric surface area $S$. All potentials are quoted versus SCE ( $0.242 \mathrm{~V}$ vs. NHE).
Raman spectroscopy. Raman spectra were recorded with a Labram microscope (Horiba Jobin-Yvon) equipped with a 1ox objective and a $633 \mathrm{~nm}$ excitation wavelength. Ex situ measurements were performed on dried GLAD electrodes, with $30 \mathrm{~s}$ integration time. In situ Raman microscopy was achieved in a home-made spectroelectrochemical cell adapted from the literature, 35 with a thin Pt wire as counter electrode and an $\mathrm{Ag} / \mathrm{AgCl} / \mathrm{KCl}$ sat. reference electrode (DriRef, WPI Int.). The surface of the GLAD-electrode was 0.35 $\mathrm{cm}^{2}$ and the volume of electrolyte was $200 \mu \mathrm{L}$. The spectra presented in Figure 4 are the average of 5 individual spectra each recorded with a $15 \mathrm{~s}$ exposure time.

\section{RESULTS AND DISCUSSION}

\section{Electrode characterization}

The nanostructured $\mathrm{GLAD}^{-\mathrm{TiO}_{2}}$ films (1- $\mu$ m-thick) were deposited at $72^{\circ}$ over the flat surface of a rotating glass substrate pre-coated with a $250-\mathrm{nm}$ thick titanium layer.5 The resulting nanostructured amorphous $\mathrm{TiO}_{2}$ films are characterized by a surface area enhancement (SA) of 540 for a total film mass of $0.25 \mathrm{mg} \cdot \mathrm{cm}^{-2} .4$ The conversion of these amorphous $\mathrm{TiO}_{2}$ films into crystalline anatase films was performed by thermal annealing at $400^{\circ} \mathrm{C}$ (see Experimental Section). The anatase phase was confirmed by XRD and Raman spectroscopy (Figure $\mathrm{S}_{1}$ ). The Raman spectrum exhibits four peaks centered at 144, 396, 516 and $636 \mathrm{~cm}^{-1}$, attributed to the $E_{g}, B_{1 g}, A_{1 g}$ or $B_{1 g}$, and $E_{g}$ vibration modes of anatase, respectively. ${ }^{36}$ Both the position and linewidth of the first $E_{\mathrm{g}}$ mode are highly sensitive to the crystallite size, and the present values $\left(v=144 \mathrm{~cm}^{-1}\right.$; fwhm $\left.=15 \mathrm{~cm}^{-1}\right)$ are consistent with a crystallite size close to $10 \mathrm{~nm} .37$ Further characterization of the anatase film morphology was achieved using different microscopy techniques. The SEM images of both amorphous and anatase electrodes show no major evolution of the film thickness after crystallization (see Figure 1), but wider posts were observed together with a much smoother surface and increased spacing between posts. This later observation is further confirmed by AFM imaging (Figure S2), where inter-columnar gaps are shown to take up a greater fraction of the geometrical area, and which is most likely associated with a denser structure and the closure of nano- and micropores. Finally, ex situ and in situ TEM analysis further confirms conversion from an assembly of nanoparticle-like structures that make up the GLAD posts to large, facetted anatase crystallites (Figure 1). The nanoparticles' average diameter is estimated to increase from $4 \pm 0.2$ to $11 \pm 2 \mathrm{~nm}$ upon crystallization, this later value being consistent with that estimated from the Raman spectrum. Such a significant increase in the average nanoparticle diameter upon crystallization was also reported in other studies. $3^{8}$ Assuming spherical nanoparticles, the surface area enhancement of the GLAD film was estimated on the basis of simple geometric considerations to be decreased by a factor 2.5 after thermal annealing.

The GLAD- $\mathrm{TiO}_{2}$ electrodes were first characterized by cyclic voltammetry in an inert $0.5 \mathrm{M} \mathrm{KCl}$ electrolyte ( $\mathrm{pH}$ 5.0). Under these experimental conditions (i.e., in the absence of inserting cations), the semiconductive nanostructured $\mathrm{TiO}_{2}$ film is expected to switch from an insulating state to a metallike conductive state once the applied potential $E$ is swept 


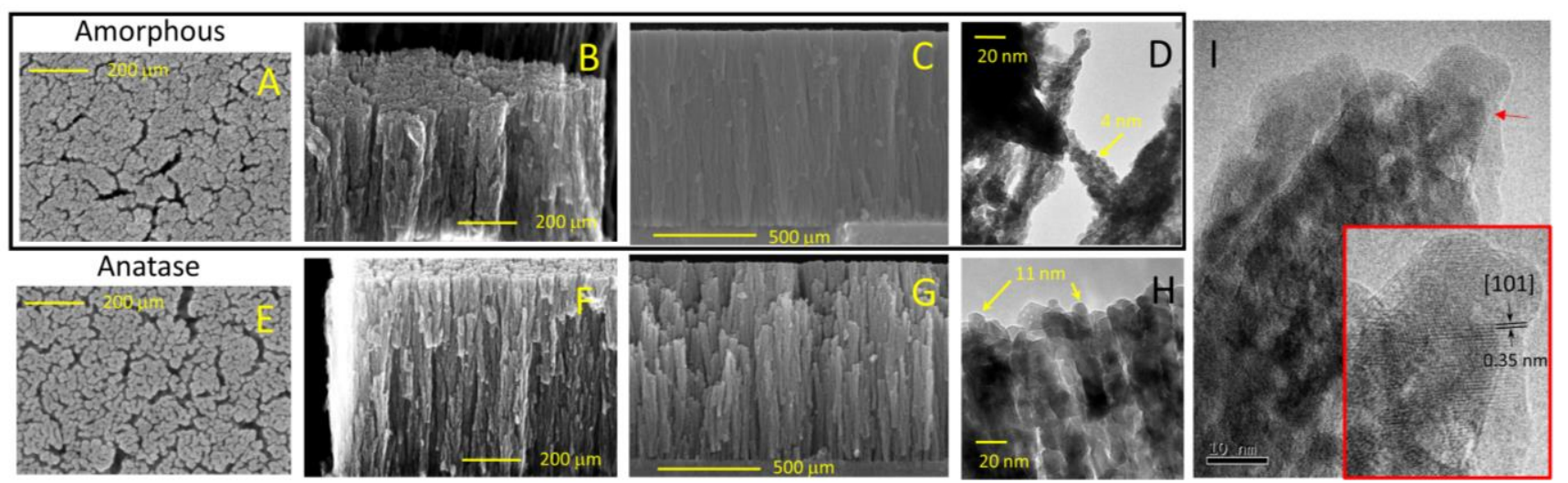

Figure 1. Scanning electron microscopy (SEM) and transmission electron microscopy (TEM) images obtained at the GLAD-TiO, electrodes (A to D) before and (E to I) after thermal annealing at $400^{\circ} \mathrm{C}$. (A, E) Top-view SEM images. (B, C, F, G) Cross-sectional SEM images. (D, H) Ex situ and (I) in situ TEM images recorded on a portion of the film scraped from the Ti substrate and showing formation of the large facetted crystallites with anatase phase structure.

from above the conduction band potential $\left(E_{\mathrm{CB}}\right)$ of $\mathrm{TiO}_{2}(E>$ $E_{\mathrm{CB}}$ ) to a potential below $E_{\mathrm{CB}}$ (which means that at $E<E_{\mathrm{CB}}$, the porous film of $\mathrm{TiO}_{2}$ behaves like a large surface area porous conductive electrode). 4 The cyclic voltammograms (CVs) for the amorphous and anatase films recorded in $\mathrm{KCl}$ at various scan rates are shown in Figure 2A. They display similar shapes, showing a sudden exponential current increase during the forward reductive scan when the applied potential reaches an onset value close to $E_{\mathrm{CB}}$ (i.e., at $\sim-0.5 \mathrm{~V}$ vs. SCE). The currents then stabilize to near-constant values for more negative potentials. This behavior is characteristic of the transition of $\mathrm{TiO}_{2}$ from an insulating to a conductive state, wherein the near-stable current $\left(i_{C}\right)$ reached at potentials lower than $-0.5 \mathrm{~V}$ (i.e., at $E<E_{\mathrm{CB}}$ ) is directly linked to the double layer capacitance of the nanoporous conductive film according to the following relationships:

$$
i_{C}= \pm S_{a} C_{d l} v \quad \text { or } \quad j_{C}=\frac{i_{C}}{S}= \pm(S A) C_{d l} v
$$

where $S_{a}$ is the specific electroactive area of the $\mathrm{TiO}_{2}$ film (i.e., $S_{a}=S A \times S$ in $\mathrm{cm}^{2}$, where $S$ is the geometric electrode area), $C_{d l}$ the double-layer differential capacitance of $\mathrm{TiO}_{2}$ (in $\mathrm{F} \cdot \mathrm{cm}^{2}$ ), and $v$ the scan rate (in $\mathrm{V} \cdot \mathrm{s}^{-1}$ ). During the reverse scan, the current returns almost symmetrically to its starting value. Also noteworthy is the appearance of an irreversible cathodic faradic contribution at potentials below -1.0 V, which becomes more pronounced as the scan rate is gradually reduced. We attribute this to the hydrogen evolution reaction (HER), which arises from the direct irreversible reduction of water to $\mathrm{H}_{2}$ at the $\mathrm{TiO}_{2} /$ electrolyte interface.

In order to perform a quantitative analysis of the capacitive current in the potential region where $\mathrm{TiO}_{2}$ is fully conductive, we plotted the cathodic current at $-1.0 \mathrm{~V}$ (a potential value where the HER contribution remains small) as a function of the scan rate (Figure $2 \mathrm{~B}$ ). The experimental data from amorphous and anatase electrodes show a perfect linear relationship between the current density and scan rate, which supports the validity of eq. 1 and thus fast charging of the $\mathrm{TiO}_{2}$ double-layer capacitance without significant Ohmic drop within the film mesoporosity (at least within the investigated range of scan rates). This result thus confirms fast electron transport throughout the conductive $\mathrm{TiO}_{2}$ film (i.e. at $E<E_{\mathrm{CB}}$ ), regardless of its crystallinity. Such behavior allows us to use eq. 1 to determine the specific surface area of $\mathrm{TiO}_{2}$ from the knowledge of $C_{d l}$ or vice-versa. 39 Since the surface area enhancement of the amorphous GLAD-TiO ${ }_{2}$ film has been well-established from previous works (i.e., $S A=540$, determined by BET), 34 we can deduce $C_{d l}$ from the slope of the linear regression fit in Figure $2 \mathrm{~B}$. A value of $32 \mu \mathrm{F} \cdot \mathrm{cm}^{-2}$ is obtained, which is identical to our previously published value for similar amorphous GLAD$\mathrm{TiO}_{2}$ electrodes, 4 a result that finally confirms the excellent batch-to-batch reproducibility of the GLAD process. It is also interesting to note that this $C_{d l}$ value is close to that reported for nanocrystalline films of anatase (i.e., consisting of sintered anatase nanoparticles with a diameter of $4 \mathrm{~nm}$ ) in an
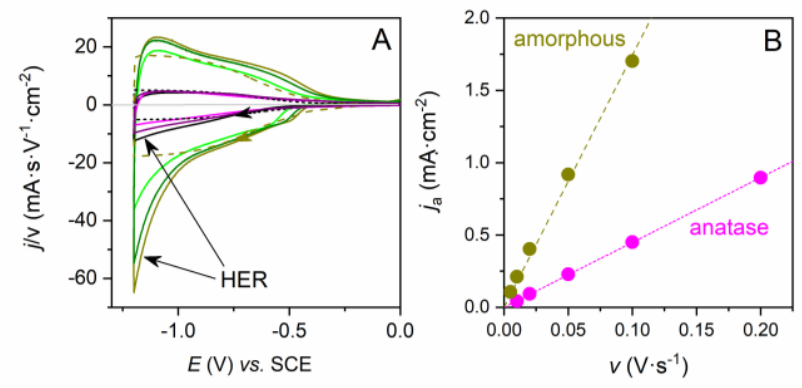

Figure 2. Electrochemical features at an (dark yellow to green) amorphous and (black to magenta) anatase GLAD- $\mathrm{TiO}_{2}$ electrode in an aqueous electrolyte containing $0.5 \mathrm{M} \mathrm{KCl}$ and adjusted with $\mathrm{HCl}$ to $\mathrm{pH}$ 5.o. (A) Normalized CVs (i.e., normalized to the scan rate $v$ ) recorded at (dark yellow and black) 10, (olive and purple) 20 and (green and magenta) $100 \mathrm{mV} \cdot \mathrm{s}^{-1}$. The dashed and dotted curves correspond to the numerically simulated capacitive CVs in the absence of HER (see SI for details). (B) Scan rate dependence of the capacitive current density $(j c)$ measured at $-\mathbf{1 . 0} \mathrm{V}$. The dashed lines are the linear regression fits passing through zero, leading to slopes of 17.4 and $4.5 \mathrm{~mA} \cdot \mathrm{s} \cdot \mathrm{V}^{-1} \cdot \mathrm{cm}^{-2}\left(r^{2}=0.999\right.$ and 0.998$)$ for the amorphous and anatase electrodes, respectively. 
acetonitrile electrolyte. ${ }^{\circ}$ We can therefore conclude that $C_{d l}$ does not change significantly with the degree of crystallinity of $\mathrm{TiO}_{2}$ and, consequently, that the present value can be used to estimate the surface area of any nanostructured $\mathrm{TiO}_{2}$ electrode via eq. 1. Accordingly, the systematically lower capacitive currents obtained here with the anatase films with respect to the amorphous ones (Figure 2) undoubtedly attest to a significant decrease in the specific surface area of GLAD electrodes after annealing and recrystallization. This decrease can be rationalized by the loss of nano- and/or microporosity, especially at the grain boundaries, due to the growth of the $\mathrm{TiO}_{2}$ nanoparticles during thermal annealing (a behavior we clearly highlight from the analysis of the SEM images in Figure 1). For the anatase film, a $S A$ value of 150 was derived from the linear regression slope in Figure $2 \mathrm{~B}$, which is 3.6-fold lower than for the amorphous film. This ratio is consistent with the conclusions we have just drawn above from the microscopic analysis of the film morphology.

\section{Reversible electrochemical proton insertion}

The amorphous and anatase $\mathrm{GLAD}-\mathrm{TiO}_{2}$ electrodes were next investigated by $\mathrm{CV}$ in a $1 \mathrm{M}$ acetate buffer electrolyte of $\mathrm{pH}$ 5.0 (Figure $3 \mathrm{~A}$ and $\mathrm{S}_{3}$ ). For both electrodes, in the potential window where $\mathrm{TiO}_{2}$ is fully conductive, the current density is considerably increased compared to that previously obtained in the unbuffered electrolyte (compare plain and dashed colored lines in Figure $3 \mathrm{~A}$ ). These current increases are directly related to the growth of a pair of reversible peaks, either broad or sharp, characteristic of a faradaic charge storage process resulting from the following reversible proton insertion-coupled electron transfer reaction: 4,5

$\mathrm{Ti}^{\mathrm{IV}} \mathrm{O}_{2}+x \mathrm{e}^{-}+x \mathrm{AH} \leftrightarrows \mathrm{Ti}^{\mathrm{IV}}{ }_{1-x} \mathrm{Ti}^{\mathrm{iII}}{ }_{x}(\mathrm{O})_{1-x}(\mathrm{OH})_{x}+x \mathrm{~A}^{-}$

where $\mathrm{AH}$ and $\mathrm{A}^{-}$stand for the Brønsted weak acid and conjugate base of the buffer (i.e. acetic acid and acetate in the present case).

From integration of the cathodic or anodic peak currents in Figure $3 \mathrm{~A}$, the amount of charge reversibly stored in each type of $\mathrm{TiO}_{2}$ electrode can be estimated. Similar reversible gravimetric capacities are obtained for the anatase and amorphous electrode, i.e., $132 \mathrm{~mA} \cdot \mathrm{h} \cdot \mathrm{g}^{-1}$ and $144 \mathrm{~mA} \cdot \mathrm{h} \cdot \mathrm{g}^{-1}$, respectively. These reversible protonation capacities correspond to a proton stoichiometry of $x>0.4$, which is close to the stoichiometry of $x=0.5$ commonly encountered with the insertion of $\mathrm{Li}^{+}$in $\mathrm{TiO}_{2}$, clearly attesting to a bulk insertion mechanism. (It is interesting to note that from integration of the peak currents shown in Figure $3 \mathrm{~B}$ with the reversible insertion of $\mathrm{Li}^{+}$in the anatase electrode, a value 125 $\mathrm{mA} \cdot \mathrm{h} \cdot \mathrm{g}^{-1}$ is obtained, which is close to those obtained with the insertion of $\mathrm{H}^{+}$.) However, unlike $\mathrm{Li}^{+}$insertion, $\mathrm{H}^{+}$ insertion in $\mathrm{TiO}_{2}$ is associated with a rather poor Coulombic efficiency $(C E)$, i.e. $67 \%$ and $24 \%$ for the amorphous and anatase GLAD $\mathrm{TiO}_{2}$ electrodes, respectively. This poor $C E$ is the consequence of the competitive HER, which increasingly occurs when the applied potential reaches sufficiently negative values (thus leading to these irreversible increases in current at the end of the reductive scans). The HER is more clearly discernible at the anatase electrode (see the net exponential increase of the cathodic current below $-1.4 \mathrm{~V}$ in
Figure $3 \mathrm{~A}$ ) mainly because in this case the potential is scanned to more negative values (thus explaining the poorer $C E$ value for anatase).

Irrespective of the proton storage capacity, the shapes and potential positions of the CVs obtained with the amorphous film compared with the crystalline $\mathrm{TiO}_{2}$ film (Figure $3 \mathrm{~A}$ and
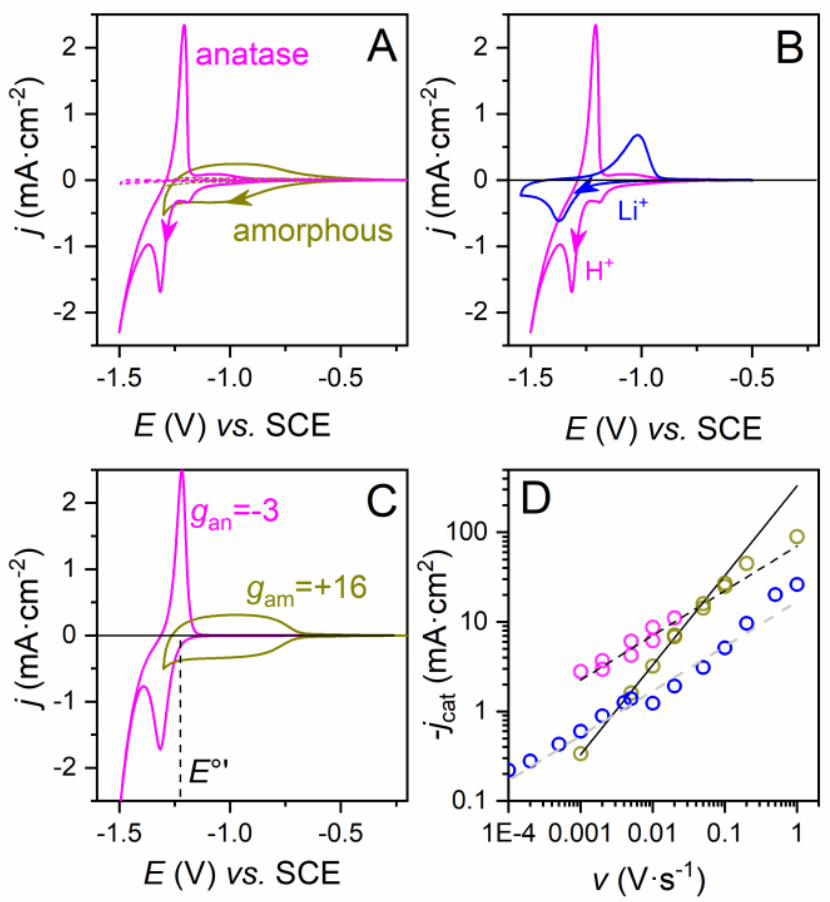

Figure 3. (A) Experimental CVs recorded at an (dark yellow) amorphous and (magenta) anatase $\mathrm{GLAD}-\mathrm{TiO}_{2}$ electrode immersed in an aqueous electrolyte ( $\mathrm{pH}$ 5.0) made of (dashed curves) $0.5 \mathrm{M} \mathrm{KCl}$ or (solid curves) $1 \mathrm{M}$ acetate buffer. (B) Experimental CVs recorded at anatase $\mathrm{GLAD}_{-} \mathrm{TiO}_{2}$ electrodes in a (magenta) $1 \mathrm{M}$ acetate buffer or (blue) $1 \mathrm{M} \mathrm{LiClO}_{4}$ acetonitrile electrolyte. (C) Numerically simulated CVs of an (dark yellow) amorphous and (magenta) anatase $\mathrm{TiO}_{2}$ electrode in a $1 \mathrm{M}$ acetate buffer (see text and SI for details). The scan rate for all CVs is $1 \mathrm{mV} \cdot \mathrm{s}^{-1}$. (D) Scan rate dependence of the cathodic peak current densities recorded at amorphous and anatase GLAD $\mathrm{TiO}_{2}$ electrodes (same color code as in (A) and (B)). The straight dashed lines are the fits of eq 5 to the experimental data using: (black) $D_{\mathrm{H}, \text { in }}=4 \times 10^{-15} \mathrm{~cm}^{2} \cdot \mathrm{s}^{-1}$ or (grey) $D_{\mathrm{Li}, \text { in }}=3 \times 10^{-16} \mathrm{~cm}^{2} \cdot \mathrm{s}^{-1}$. The solid black line that fits the low scan rate data recovered from the amorphous $\mathrm{GLAD}^{-\mathrm{TiO}_{2}}$ electrode has a slope of 1 .

$\mathrm{S}_{3}$ ) show a striking contrast. The CVs recorded at anatase exhibit a pair of well defined, reversible and sharp faradaic peaks, centered on a mid-point potential $\left(E_{1 / 2}\right)$ of $-1.26 \mathrm{~V}(v s$. SCE), which is very different from the amorphous film showing very broad faradaic bumps located at $E_{1 / 2}=-1.04 \mathrm{~V}$. Such contrasting behavior indicates that the proton insertion reaction in $\mathrm{TiO}_{2}$ is, from a thermodynamic point of view, not equivalent between the amorphous and crystalline phases of $\mathrm{TiO}_{2}$. These divergences can be phenomenologically taken into account using the well-established concept of the Frumkin intercalation isotherm, which considers energetic interactions between insertion sites.41,42 In that context, the equation governing the equilibrium potential of $\mathrm{TiO}_{2}$ as a 
function of its redox state through reaction 2 is given by the following modified Nernst equation:

$E_{e q}=E_{\mathrm{TiO}_{2} / \mathrm{TiOOH}}^{0}-2.302 \frac{R T}{F} \mathrm{pH}+\frac{R T}{F} g \theta+\frac{R T}{F} \ln \left(\frac{\theta}{1-\theta}\right)$ (3)

where $(1-\theta)$ corresponds to the state-of-protonation (i.e., the fraction of protons inserted into the lattice relative to the maximal number of insertion sites), $E_{\mathrm{TiO}_{2} / \mathrm{TiOOH}}^{0}$ is the standard potential of the $\mathrm{TiO}_{2} / \mathrm{TiOOH}$ couple (in $\mathrm{V}$ ), and $g$ is the Frumkin parameter characterizing the mean interaction energy between the intercalation sites (positive for repulsion and negative for attraction). From this modified version of the Nernst equation, we can also define the mid-point potential $E_{1 / 2}$ at $\theta=0.5$ :

$$
E_{1 / 2}=E_{\mathrm{TiO}_{2} / \mathrm{TiOOH}}^{0}-2.302 \frac{R T}{F} \mathrm{pH}+0.5 \frac{R T}{F} g
$$

Under thermodynamic equilibrium, this latter expression allows us to access the $g$ parameter once both the $\mathrm{pH}$ of the electrolyte and the standard potential of the $\mathrm{TiO}_{2} / \mathrm{TiOOH}$ couple are known. Within this framework, a critical value of $g_{\text {crit }}=-4$ marks the limit where the solid solution insertion process switches to an insertion process driven by a firstorder phase transition with a zero-height energetic barrier. ${ }^{4}$ On account of the slow scan rate used to record the CVs in Figure $3 \mathrm{~A}$, we assume that the insertion reaction occurs under almost thermodynamic equilibrium. Under these conditions, the noticeable difference between the two midpoint potentials characterizing the reversible insertion of protons in the amorphous and anatase electrode (i.e., $E_{1 / 2}=-$ 1.04 $\mathrm{V}$ and $-1.26 \mathrm{~V}$, respectively), indicates a significant $\Delta g$ value difference between the amorphous and crystalline phases of $\mathrm{TiO}_{2}$ (a $\Delta g$ of $\sim 17$ can be estimated on the basis of the $\Delta E_{1 / 2}$ of $-0.22 \mathrm{~V}$ ).

The results obtained here are strongly reminiscent of what was observed with the reversible $\mathrm{Li}^{+}$insertion in $\mathrm{TiO}_{2}$-based electrodes. ${ }^{28,43-53}$ In anatase, it was established that $\mathrm{Li}^{+}$ insertion is accompanied by a reversible phase transition from a lithium-poor tetragonal phase to a lithium-rich orthorhombic $\mathrm{Li}_{\sim 0.5} \mathrm{TiO}_{2}$ phase. ${ }^{28,47}$ This translates into a pair of well-defined faradaic peaks in $\mathrm{CV}$, separated by a significant potential hysteresis under thermodynamic equilibrium (peak-to-peak potential separation $\Delta E_{p}>0$ ), 43,46 as also reported here in Figure $3 \mathrm{~B}$. In the Frumkin framework, such a phase transformation is thus associated with $g<g_{\text {crit. }}{ }^{42}$ On contrario, the insertion of $\mathrm{Li}^{+}$in amorphous $\mathrm{TiO}_{2}$ was characterized by a pair of symmetric but very broad faradaic waves in CV (meaning thus a $g$ value $>$ o),44,45,48-53 leading some groups to conclude that in amorphous $\mathrm{TiO}_{2}$, the reversible $\mathrm{Li}^{+}$insertion proceeded through a solid solution reaction over a distribution of insertion potentials (reflecting the highly disordered structure of $\left.\mathrm{TiO}_{2}\right) .44,54$

To better understand the dynamics of the proton insertioncoupled electron transfer reaction, CVs were recorded at different scan rates ranging from $1 \mathrm{mV} \cdot \mathrm{s}^{-1}$ to $1 \mathrm{~V} \cdot \mathrm{s}^{-1}$ (Figure $\mathrm{S}_{3}$ ). All electrodes display a comparable scan rate dependence of $\Delta E_{p}$ (Figure $\left.\mathrm{S}_{4}\right)$. At the slowest scan rates, the $\Delta E_{p}$ values tend to a constant positive value $\left(\Delta E_{p}>0\right)$, suggesting that the electrochemical reaction has reached the thermodynamic equilibrium. This non-zero value of $\Delta E_{p}$ however does not agree with the Nernst equation (eq. 3) for which no voltage gap between the anodic and cathodic peak is expected under thermodynamic control of ion insertion. Such behavior echoes what has also been observed with reversible $\mathrm{Li}^{+}$ insertion in anatase, leading below $1 \mathrm{mV} \cdot \mathrm{s}^{-1}$ to a stable and large peak-to-peak separation in CV (Table S2). The non-zero value of $\Delta E_{p}$ observed at equilibrium in $C V$ was proposed as a diagnostic criterion for a phase transformation of the active electrode material during an ion insertion, and its magnitude reflects the energetic barrier associated with nucleus formation. ${ }^{42}$ In the present case of reversible $\mathrm{H}^{+}$insertion, a significantly lower $\Delta E_{p}$ value is observed, thus suggesting that the associated phase transformation occurs through a less energetic nucleation barrier than with $\mathrm{Li}^{+}$. This observation is fully consistent with the minor orthorhombic distortion predicted between anatase and the $\mathrm{H}_{0.5} \mathrm{TiO}_{2}$ crystalline structures. 55 Upon increasing the scan rate, the exponential growth of $\Delta E_{p}$ indicates an electrochemical process increasingly rate-controlled by interfacial protoncoupled electron transfer kinetics, and most likely includes a contribution of the residual uncompensated Ohmic drop at the highest scan rates.

Plotting the cathodic peak current as a function of the scan rate (Figure $3 \mathrm{D}$ ) reveals a behavioral distinction between the amorphous and anatase film. Indeed, with the former the cathodic peak current density scales linearly with $v$ (slope 1 in $\log$-log scale), while with the latter it scales linearly with $\sqrt{v}$ (slope 0.5), and this is observed for both proton and $\mathrm{Li}^{+}$ insertion. These results suggest that the rate of solid-state proton diffusion across the amorphous $\mathrm{TiO}_{2}$ is not rate limiting (at least in the scan rate range 1 to $50 \mathrm{mV} \cdot \mathrm{s}^{-1}$ ). On contrario, the slope of 0.5 with anatase suggests a diffusioncontrolled $\mathrm{H}^{+}$insertion within the bulk of $\mathrm{TiO}_{2}$, remaining in this case valid over the whole range of scan rates investigated. Such a difference between the apparent dynamic of proton insertion in anatase and amorphous electrodes is reminiscent of what has been reported in the literature for $\mathrm{Li}^{+}$insertion in amorphous vs. anatase $\mathrm{TiO}_{2}$ electrodes.44,51,53 Indeed, as for proton insertion at slow scan rates, insertion of $\mathrm{Li}^{+}$in amorphous $\mathrm{TiO}_{2}$ is not controlled by the mass transport of $\mathrm{Li}^{+}$in the solid phase, in contrast to $\mathrm{Li}^{+}$ insertion in anatase. It was therefore concluded that $\mathrm{Li}^{+}$ diffuses more rapidly in the amorphous phase than in the anatase phase (by ca. two orders of magnitude). However, these analyses were performed without rigorously taking into account the true specific surface area developed by the initial amorphous phase compared with that developed by anatase after thermal crystallization, which can be very different. Here, we will demonstrate that the difference in slope observed on the plots of Figure $3 \mathrm{D}$ is not due to a difference in the diffusion rate of the cation in the two phases, but rather results from a difference in the electroactive surface area developed by each of the GLAD-TiO $\mathrm{T}_{2}$ electrodes.

In order to roughly estimate the apparent solid-state diffusion coefficient of $\mathrm{H}^{+}$in the anatase GLAD film, we have used the following modified Randles-Sevcik equation 
(previously established by us from a simple continuum $1 \mathrm{D}$ two-compartment model with an isotropic diffusion of the species in each compartment $\left.4^{\circ}\right)$ :

$$
j_{p, c}=\frac{i_{p, c}}{S}=0.446 F(S A) x C_{\mathrm{Ti}}^{0} \sqrt{D_{\mathrm{H}, \text { in }} F v / R T}
$$

where $j_{p, c}$ is the faradaic current density of the cathodic peak current (normalized to the geometric electrode area $S$ ), $F$ the Faraday constant $\left(96485 \mathrm{C}^{\mathrm{mol}}{ }^{-1}\right), C_{\mathrm{Ti}}^{0}$ the maximal concentration of $\mathrm{Ti}$ ions in $\mathrm{TiO}_{2}$ (i.e., $0.048 \mathrm{~mol} \cdot \mathrm{cm}^{-3}$ ), $x$ the maximal mole fraction of protons that can reversibly insert in the fully reduced phase ( $x$ is assumed equal to $0.5^{56}$ ), and $D_{\mathrm{H} \text {,in }}$ the apparent solid-state diffusion coefficient of $\mathrm{H}^{+}$in the metal oxide lattice during insertion. Assuming a $S A$ value of 150 for anatase (see above), a $D_{\mathrm{H} \text {,in }}$ of $4 \times 10^{-15} \mathrm{~cm}^{2} \cdot \mathrm{s}^{-1}$ can be inferred from the fit of eq. 5 to the experimental cathodic peak currents plotted in Figure 3D. Despite the contribution of HER to the faradaic insertion peak, the $D_{\mathrm{H}, \text { in }}$ value determined here for the anatase electrode remains close to the one we had previously determined at amorphous GLAD $\mathrm{TiO}_{2}$ films $\left(1 \mathrm{O}^{-15} \mathrm{~cm}^{2} \cdot \mathrm{s}^{-1}\right) .4,56$ This result strongly suggests that proton migration/diffusion within the crystalline phase of $\mathrm{TiO}_{2}$ occurs at a similar rate as within the amorphous phase. Using the same eq. 5 to fit the data obtained in Figure ${ }_{3} \mathrm{D}$ with $\mathrm{Li}^{+}$, a $D_{\mathrm{Li} \text {,in }}$ value of $3 \times 10^{-16} \mathrm{~cm}^{2} \cdot \mathrm{s}^{-1}$ was recovered, which is one order of magnitude lower than the corresponding value for protons. It is worth noting that, strictly speaking, eq. 5 is only valid for a reversible electron transfer reaction associated with a solid solution insertion process, wherein the inserted cation is assumed to homogenously diffuse throughout the solid phase. Therefore, it is not normally applicable to an electrode material undergoing phase transformations, which is typically the case with the insertion of $\mathrm{Li}^{+}$in anatase. Still, the present $D_{\mathrm{Li}, \text { in }}$ value is close to that predicted by first-principles calculations for $\mathrm{Li}^{+}$diffusion in the orthorhombic $\mathrm{Li}_{0.5} \mathrm{TiO}_{2}$ phase. 57

In order to move towards a more quantitative analysis of the CVs, we next considered the possibility of simulating them from our previously published one-dimensional twocompartment model. $5^{6}$ The model takes into account the following three-step process: $(i)$ the $1 \mathrm{D}$ diffusion/convection mass transport of the proton donor/acceptor in the electrolyte compartment, (ii) the heterogeneous protoncoupled electron transfer reaction at the boundary metal oxide/electrolyte interface separating the two compartments, and (iii) the $1 \mathrm{D}$ diffusional mass transport of $\mathrm{H}^{+}$within the solid metal oxide compartment. An important aspect of this model is the geometric equivalence used to convert the mesoporous GLAD film-coated electrode to a simpler bulk thin-film electrode, as sketched in Scheme 1 and expressed through eq. Si. It not only allows for a simpler model but it also defines the maximal penetration length $d_{a}$ of protons in $\mathrm{TiO}_{2}$. Taking into account the fact that the specific surface area of the anatase GLAD film is significantly reduced compared with that of the original amorphous film, it can be calculated that the inserted protons have to diffuse through a greater thickness of bulk $\mathrm{TiO}_{2}$ with the anatase $\left(d_{a}=4.3 \mathrm{~nm}\right)$ than with the amorphous film $\left(d_{a}=1.2 \mathrm{~nm}\right)$. Consequently, if an identical value of $D_{\mathrm{H} \text {,in }}$ is assumed in both materials, the time required (i.e., $t=d_{a}^{2} / D_{\mathrm{H}, \mathrm{in}}$ ) to fully protonate $\mathrm{TiO}_{2}$ is significantly reduced for the amorphous film compared to that of anatase (by a factor > 10). It is worth noting that the calculated $d_{a}$ values are in good agreement with the average grain sizes estimated from the TEM images (see Figure 1). In addition, we have included in our model the capacitive contribution to the overall current. Within this

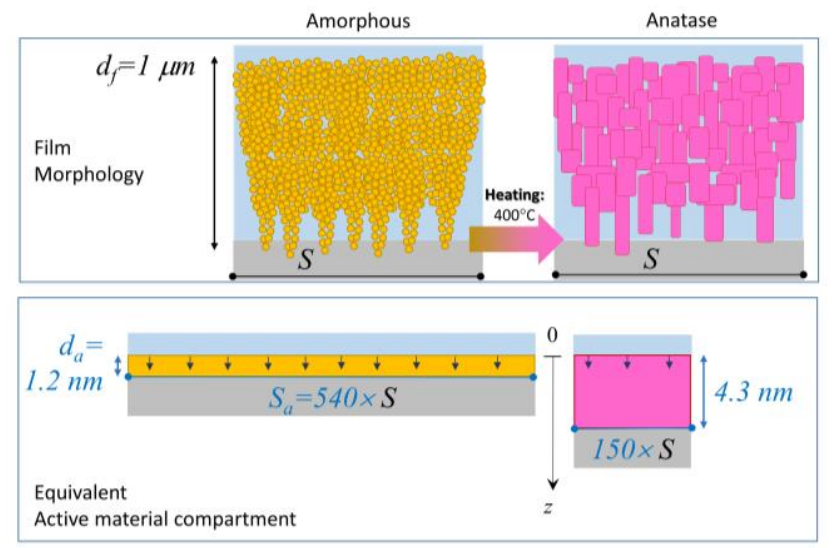

Scheme 1. (top) Representation of the nanostructured GLAD- $\mathrm{TiO}_{2}$ electrode morphology (dark yellow) before and (magenta) after thermal annealing as deduced from the microscopy imaging, and (bottom) equivalent bulk thin-filmcoated electrode illustrating the maximal penetration length of protons within the bulk $\mathrm{TiO}_{2}$.

framework and according to the methodology detailed in the SI, we first successfully simulated the purely capacitive contribution in the CVs (see dashed curves in Figure 2A). For such a purpose, we used the $C_{d l}$ and $S A$ values determined above and then iteratively adjusted the conduction band potential value, $E_{\mathrm{CB}}$, of each $\mathrm{TiO}_{2}$ phase. From the best fit of the simulated curves to the experimental CVs, $E_{\mathrm{CB}}$ values of $0.51 \mathrm{~V}$ and $-0.65 \mathrm{~V}$ were finally recovered for the amorphous and anatase phases, respectively (Table Si).

We next simulated the CVs in the presence of a proton donor and acceptor (i.e., in the presence of a buffer) in the electrolyte compartment, thus generating, in addition to the capacitive current, a faradaic current associated with the reversible insertion of protons into the solid phase. The model detailed in the SI is similar to the one we had previously reported, ${ }^{6}$ except for the boundary conditions at the $\mathrm{TiO}_{2}$ /electrolyte interface (at $z=0$ ) where the standard Butler-Volmer equation was here combined with a Frumkintype intercalation isotherm to account for the average interactions between the intercalation sites in $\mathrm{TiO}_{2}$, thus leading to eq. $\mathrm{S}_{7}$.

In addition to the capacitive and faradaic current contributions, we have also included in the model the irreversible current response resulting from the HER (see SI for details). The model was solved numerically by a finite difference method implemented in the software Comsol 
Multiphysics (see SI), allowing us to simulate and predict the $\mathrm{CV}$ plots for any parameter conditions. The simulated CVs shown in Figure $3 \mathrm{~A}$ were obtained using the set of parameters listed in Table S1. The shape, amplitude and potential position of the computed CVs at $1 \mathrm{mV} / \mathrm{s}$ are in quite good agreement with those obtained experimentally, for both the anatase and amorphous GLAD $\mathrm{TiO}_{2}$ electrodes (Figure $3 \mathrm{C}$ ), indicating that our model is suitable for replicating not only qualitatively but also, to some extent, quantitatively the experimental data. From the best set of parameters used to simulate the CVs (see Table $\mathrm{S}$ ), the following important information were drawn:

(1) whatever the $\mathrm{TiO}_{2}$ electrode, the CVs were appropriately simulated using a unique standard potential value for the $\mathrm{Ti}^{\mathrm{IV}} \mathrm{O}_{2} / \mathrm{Ti}^{\mathrm{iII}} \mathrm{OOH}$ couple (i.e. $E_{\mathrm{TiO}_{2} / \mathrm{TiOOH}}^{0}=-0.94 \mathrm{~V}$ vs. SCE), a result which supports that the intrinsic thermodynamics associated with the redox-active couple $\mathrm{Ti}^{\mathrm{IV}} / \mathrm{Ti}^{\mathrm{III}}$ in $\mathrm{TiO}_{2}$ is the same for the amorphous and anatase structures.

(2) the interfacial charge transfer kinetics are also not very different for the two phases, which is understandable if we consider that the concerted proton-electron charge transfer reaction is achieved at solid interfaces of same physico-chemical nature.

(3) the factor accounting for the main differences observed between the CVs of amorphous and anatase electrodes is the Frumkin $g$ parameter. The latter is positive for amorphous $\mathrm{TiO}_{2}\left(g_{a m}=+16\right.$, meaning repulsive interactions between insertion sites) and negative for anatase $\left(g_{a n}=-3\right.$, suggesting attractive interactions). These two values of opposite sign are consistent with the reversible pair of proton insertion peaks, very broad and spreadout in the case of amorphous $\mathrm{TiO}_{2}$, while sharper and better defined in the case of anatase. In addition, $g_{\text {an }}$ is close to the critical value $g_{\text {crit }}=-4$ characterizing a phase transition, which therefore suggests that proton insertion in anatase probably occurs through a two-phase transformation.

(4) In contrast to amorphous $\mathrm{TiO}_{2}$, it was necessary to adjust the magnitude of $D_{\mathrm{H} \text {,out }}$ to a value 4 -fold higher than $D_{\mathrm{H}, \text { in }}$ to properly simulate the magnitude of the reverse disinsertion peak current with anatase, therefore suggesting an apparent solid-state proton diffusion that is faster during the discharge than during the charge. Such an observation is an additional argument in favor of a proton charge storage mechanism governed by a phase transition in anatase, for which the diffusional propagation of the two-phase transition front in the material is not necessarily identical between charge and discharge.

Despite the use of an identical proton diffusion coefficient during the charge in both phases (i.e., $D_{\mathrm{H}, \mathrm{in}}=3 \times 10^{-15} \mathrm{~cm}^{2} \cdot \mathrm{s}^{-1}$ ), the simulated insertion peak currents (not shown) were observed to vary linearly with $v$ and $\sqrt{v}$ for the amorphous $\mathrm{TiO}_{2}$ and anatase respectively, thus correlating very well with the experimental results reported in Figure $3 \mathrm{D}$. This result also clearly shows that the key parameter which governs the rate of proton insertion (and so the proportionality with $v$ or $\sqrt{v}$ ) is not the diffusion coefficient of $\mathrm{H}^{+}$in the solid matrix but the average distance $d_{a}$ that the proton must travel within the solid phase (the latter being defined by the size of grains constituting the active material).

The above results finally demonstrate that proton insertion in both anatase and amorphous $\mathrm{TiO}_{2}$ takes place according to a bulk charge storage mechanism and certainly not, as previously reported, through a near-surface charge storage process. ${ }^{23,32,33}$ The results also call into question the recently proposed notion that bulk proton insertion in titanium oxides requires hydrated or protonated layered titanate structures. ${ }^{23,24}$ Indeed, this is not consistent with our present findings where bulk proton insertion is shown to be effective even with the nonlayered and nonhydrated anatase structure (i.e., a $3^{\mathrm{D}}$ network of edge-sharing $\mathrm{TiO}_{2}$ octahedra). Additionally, one should note that the gravimetric capacities and CEs we have obtained here by CV (140 $\mathrm{mA} \cdot \mathrm{h} \cdot \mathrm{g}^{-1}$ at 10 $\mathrm{mV} / \mathrm{s}$ with $C E=68 \%$ for anatase $\mathrm{GLAD}-\mathrm{TiO}_{2}$ ) significantly exceed those previously achieved with layered titanates $(82$ $\mathrm{mA} \cdot \mathrm{h} \cdot \mathrm{g}^{-1}$ with $\mathrm{CE}=45 \%$ for $\mathrm{H}_{2} \mathrm{Ti}_{3} \mathrm{O}_{7}$ or $40 \mathrm{~mA} \cdot \mathrm{h} \cdot \mathrm{g}^{-1}$ for $\mathrm{Ti}_{3} \mathrm{O}_{7}\left(\mathrm{H}_{2} \mathrm{O}\right)_{2}$ at the same rate of $\left.10 \mathrm{mV} / \mathrm{s}\right) .{ }^{23,24}$

\section{Electrochemical performances of the $\mathrm{GLAD}-\mathrm{TiO}_{2}$ electrodes}

Proton insertion in $\mathrm{GLAD}^{-\mathrm{TiO}_{2}}$ electrodes was next investigated by galvanostatic cycling at a rate of $0.36 \mathrm{~mA} \cdot \mathrm{cm}^{-2}$ (equivalent to $1.4 \mathrm{~A} \cdot \mathrm{g}^{-1}$ ). The shapes of the galvanostatic charge/discharge curves (Figure $4 \mathrm{~A}$ ) corroborate well with the reversible waveforms recorded by $\mathrm{CV}$. For the amorphous GLAD-TiO, electrode, the charging process (i.e., proton insertion) is accompanied by a continuous increase in negative potential, which is reminiscent of the broad cathodic faradaic wave observed in CV. On contrario, with the anatase electrode, the charging potential rapidly reaches a relatively stable value at $-1.3 \mathrm{~V}$ (a more negative potential than with the amorphous $\mathrm{TiO}_{2}$, which is consistent with the CVs). This well-defined horizontal charging plateau is again indicative of a two-phase active materials transformation. ${ }^{2}$ What is interesting to point out here is that the marked contrast we observed here between the anatase and amorphous $\mathrm{TiO}_{2}$ is readily comparable to literature reports of $\mathrm{Li}^{+}$insertion from aprotic organic electrolytes.44,48-54 Concerning the discharge curves, if we disregard the interference of HER at the end of the charging processes, the curves are almost symmetrical (with respect to the charging curves) regardless of the $\mathrm{TiO}_{2}$ phase. The voltage hysteresis ( $\sim 0.05 \mathrm{~V}$ for anatase) is also quite small, indicating a fast reversible insertion reaction without significant Ohmic drop. From these galvanostatic curves, reversible gravimetric capacities of 137 and $78 \mathrm{~mA} \cdot \mathrm{h} \cdot \mathrm{g}^{-1}$ were retrieved for the amorphous and anatase electrodes, respectively. Both are however associated with a rather low CE (67 and 37\%, respectively). These low CEs are clearly associated with competitive HER which increasingly interferes at the more negative end of the galvanostatic charging processes. This HER interference is more pronounced with the anatase 
electrode simply because it needs to reach a more negative cut-off potential.

To further confirm that proton insertion in anatase is associated with a phase transformation, we investigated the structure of the electrode by in situ Raman microscopy during galvanostatic cycling (see Experimental Section for details). Raman spectroscopy is well-suited to investigating the tetragonal-to-orthorhombic phase transition of $\mathrm{TiO}_{2}$, which is associated with an increased quantity of Ramanactive modes. 58,59 The Raman spectra recorded at different $x$ values (o, 0.07 and 0.15 ) are given in Figure $4 \mathrm{~B}$. At $x=0.15$ (i.e., $55 \mathrm{~mA} \cdot \mathrm{h} \cdot \mathrm{g}^{-1}$ ), the characteristic bands of the anatase phase at 396, 516 and $636 \mathrm{~cm}^{-1}$ (see also Figure $\mathrm{S}$ ) have disappeared in favor
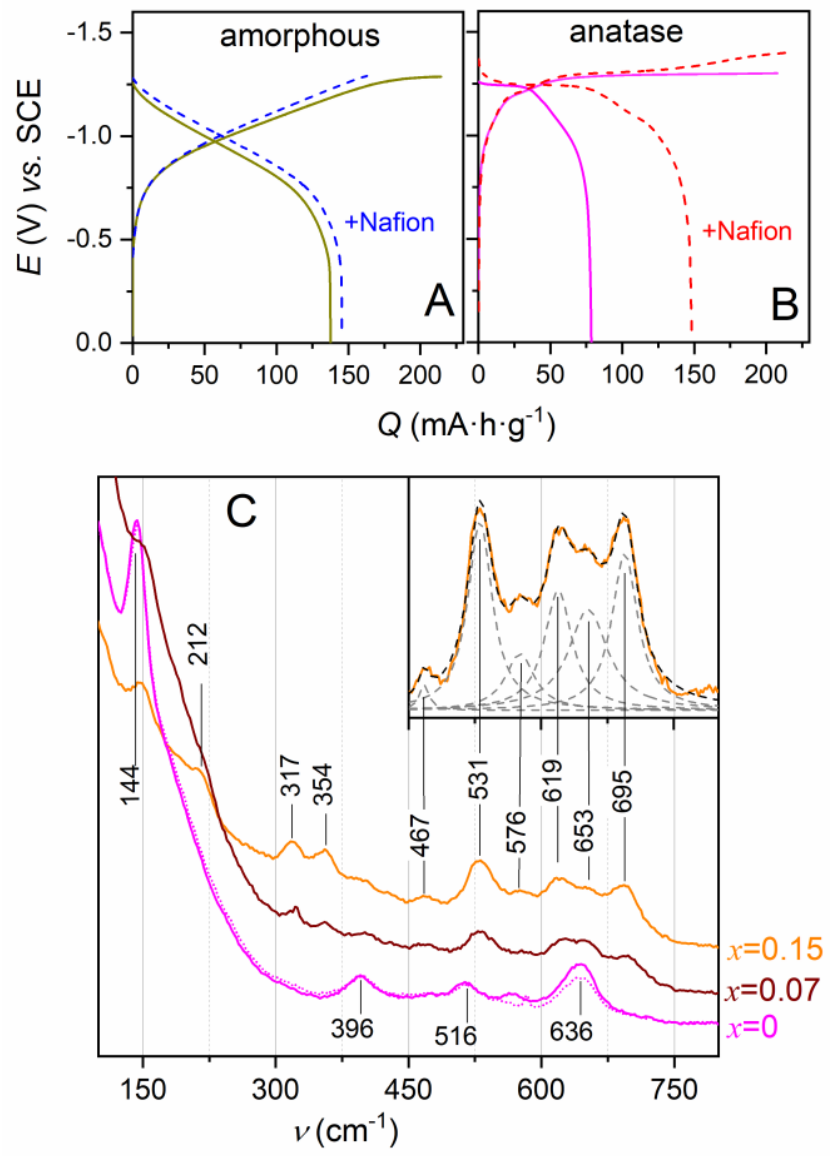

Figure 4. (Top) Galvanostatic charge and discharge curves recorded at $0.36 \mathrm{~mA} \cdot \mathrm{cm}^{-2}$ at (A) amorphous ad (B) anatase GLAD-TiO electrodes in (solid lines) the absence and (dashed lines) presence of a Nafion-film coating. (C) In situ Raman spectra of the anatase $\mathrm{GLAD}_{-} \mathrm{TiO}_{2}$ electrode, recorded over the time course of a galvanostatic cycle performed at $0.36 \mathrm{~mA} \cdot \mathrm{cm}^{-2}$ (or $1.4 \mathrm{~A} \cdot \mathrm{g}^{-1}$ ). The spectra are offset for clarity but their intensity scale is identical. The magenta lines correspond to the discharged $(x=0)$ electrode (solid) before and (dashed) after one cycle of charge/discharge.

of new bands at 212, 317 and $354 \mathrm{~cm}^{-1}$ as well as a large multicomponent band in the $45^{0}-750 \mathrm{~cm}^{-1}$ region. The latter, highlighted in the inset of Figure $4 \mathrm{~B}$, could be fitted with 6 individual Lorentzian components. Upon further increasing the protonation state of the electrode, the Raman bands completely vanish. This process is fully reversible since the initial Raman spectrum of anatase is recovered at the end of the galvanostatic cycle. Such potential-dependent Raman features, with detection of the orthorhombic phase for $x$ values as low as 0.07 , are similar to reports detailing the reversible lithiation of anatase in organic media.29,60 Furthermore, the spectrum recorded for $x=0.15$ shares several significant features with the spectra reported for orthorhombic $\mathrm{Li}_{0.5} \mathrm{TiO}_{2}$. Indeed, a similar 6-component band is reported in the $420-700 \mathrm{~cm}^{-1}$ region, of which the main components have been assigned to O-Ti-O axial and equatorial stretches,59 and shown to be strongly dependent on $\mathrm{O}$ and $\mathrm{Li}$ isotopic labelling. ${ }^{60}$ Bands at 317 and $354 \mathrm{~cm}^{-1}$ are also present in the $\mathrm{Li}_{\mathrm{x}} \mathrm{TiO}_{2}$ spectra, but with low sensitivity to isotopic labelling. Finally, by replacing $\mathrm{Li}^{+}$with $\mathrm{H}^{+}$in the orthorhombic phase, a significant upshift of the 6component band is expected, while the two bands at lower energies should remain virtually unchanged. The Raman data presented here are thus fully consistent with a tetragonal-toorthorhombic phase transformation of the crystalline $\mathrm{TiO}_{2}$ electrode during protonation.

In an attempt to improve the electrodes' performances, the GLAD- $\mathrm{TiO}_{2}$ films were coated with a protective protonconductive Nafion-layer (see Experimental section for details). Such a strategy was previously shown to be useful for improving the electrochemical performances of a negative metal hydride electrode in an alkaline aqueous electrolyte, where the Nafion coating was effective in both reducing the capacity decay and increasing the maximal discharge electrode capacity. ${ }^{61}$ The SEM images of the resulting modified electrode reveal a $3-\mu \mathrm{m}$ thick Nafion film homogeneously deposited on top of the nanostructured $\mathrm{GLAD}_{-} \mathrm{TiO}_{2}$ electrode (Figure $\mathrm{S}_{4}$ ). Under conditions preventing proton insertion (i.e., in a $0.5 \mathrm{M} \mathrm{KCl}$ electrolyte at $\mathrm{pH}$ 5.0), the CV responses of these Nafion-coated GLAD-TiO electrodes (Figure $\mathrm{S}_{5}$ ) show that the Nafion layer has a negligible effect on the double-layer capacitive current, but on the other hand, it has a significant effect for reducing/inhibiting the faradaic current associated with HER at $E<-1.1 \mathrm{~V}$. This HER inhibition effect is also present in a 1 $\mathrm{M}$ acetate buffer electrolyte (Figure S6), although it is less apparent for amorphous electrodes than for anatase electrodes. In addition, the Nafion coating affects the magnitude and separation of the faradic peaks for anatase electrodes, which are respectively slightly decreased and increased, while the overall reversibly stored charge remains almost the same. These effects suggest that the Nafion coating causes a slight increase in the charge transfer resistance, which is in line with previous reports. ${ }^{61}$ Despite this, the galvanostatic charge/discharge curves in the presence of the Nafion film show (Figure 4A) significantly improved gravimetric capacities in a $1 \mathrm{M}$ acetate buffer for both the amorphous and anatase electrodes, thus enabling up to $148 \pm 2 \mathrm{~mA} \cdot \mathrm{h} \cdot \mathrm{g}^{-1}$ (which corresponds to a stoichiometric value of $x=0.45$ ). This gain in capacity is clearly the consequence of HER inhibition, resulting in improved CEs (i.e., 87 and $68 \%$ for the amorphous and anatase electrodes, respectively). Accordingly, the $\mathrm{C}$-rate was defined as $0.15 \mathrm{~A} \cdot \mathrm{g}^{-1}$ in the following. 
The cyclability of the Nafion-coated GLAD-TiO, electrodes was next investigated under either strong or mild accumulation conditions. For strong accumulations, a $Q_{\mathrm{d}}$ of $\sim 150 \mathrm{~mA} \cdot \mathrm{h}^{-1} \mathrm{~g}^{-1}$ was selected by fixing the negative cut-off potential to $-1.3 \mathrm{~V}$ or $-1.4 \mathrm{~V}$ (for amorphous and anatase films, respectively), while for mild accumulations, a fixed charge of $100 \mathrm{~mA} \cdot \mathrm{h} \cdot \mathrm{g}^{-1}$ was applied for both electrodes during the charging step. A selection of the galvanostatic cycling curves is reported in Figure $\mathrm{S}_{7}$, and their corresponding $Q_{\mathrm{d}}$ and $C E$ values are given in Figure $5 \mathrm{~A}$ and $5_{\mathrm{B}}^{\mathrm{B}}$, respectively. In the absence of Nafion coating and under strong accumulation, the continuous galvanostatic charge/discharge curves show a rather fast and continuous capacity fading upon cycling. This is especially true for the amorphous $\mathrm{TiO}_{2}$ electrode, where half of the initial capacity is lost after 32 cycles, while the same loss is observed after 55 cycles for the anatase electrode. In each case, voltage hysteresis remains low and relatively constant, suggesting little Ohmic drop evolution and/or variation of the interfacial electron/ion transfer rates. Instead, we have attributed this continuous capacity decay to a progressive loss of the active material during cycling, which probably occurs through a slow process of corrosion and/or dissolution of $\mathrm{TiO}_{2}$. This assumption is supported by the cross-sectional images recorded by SEM/FIB on both fresh and cycled amorphous GLAD- $\mathrm{TiO}_{2}$ electrodes (Figure S8). The images reveal a lower density of active material in the cycled electrode as compared to the uncycled electrode, therefore translating to a decrease of the specific electrode surface area. This decrease in the electrode area corroborates with the capacitive $\mathrm{CV}$ responses obtained at uncycled and cycled electrodes, demonstrating in Figure S8 a net decrease in the capacitive current of the cycled electrode.

The capacity fading during cycling was also observed to be less severe under mild accumulation conditions, leading to an improved cyclability (Figure 5). These better performances are also coupled with improved CEs, suggesting that by keeping a lower degree of $\mathrm{TiO}_{2}$ protonation and/or by avoiding competitive HER, the active material is better preserved from corrosion or dissolution. Whatever the accumulation conditions, the graphs in Figure 5 clearly revealed the beneficial effect of the Nafion coating on both the Coulombic efficiency and cyclability of the GLAD-TiO ${ }_{2}$ electrode. Combining the Nafion coating with mild accumulation (100 $\mathrm{mA} \cdot \mathrm{h} \cdot \mathrm{g}^{-1}$ ) finally allows more than 100 cycles to be performed with reasonably good CEs (> $95 \%$ for amorphous $\mathrm{TiO}_{2}$ and $>80 \%$ for anatase) as well as with much slower capacity decays. The rate performances of the Nafion-coated amorphous and anatase GLAD-TiO electrodes were also evaluated during continuous galvanostatic experiments performed at different rates under mild accumulation conditions, and the results are shown in Figure 6. The observed $Q_{\mathrm{d}}$ (or $C E$ ) values were systematically lower for the anatase electrode compared to the amorphous electrode. For both electrodes, the $Q_{\mathrm{d}}$ (or $C E$ ) values increase with the charging rate, with a more pronounced ratedependence for the anatase electrode. Such a ratedependence of the $C E$ can be attributed to the kinetic competition that takes place between the fast proton insertion reaction (which is predominant at high rates) and the slower HER (which becomes more significant at lower

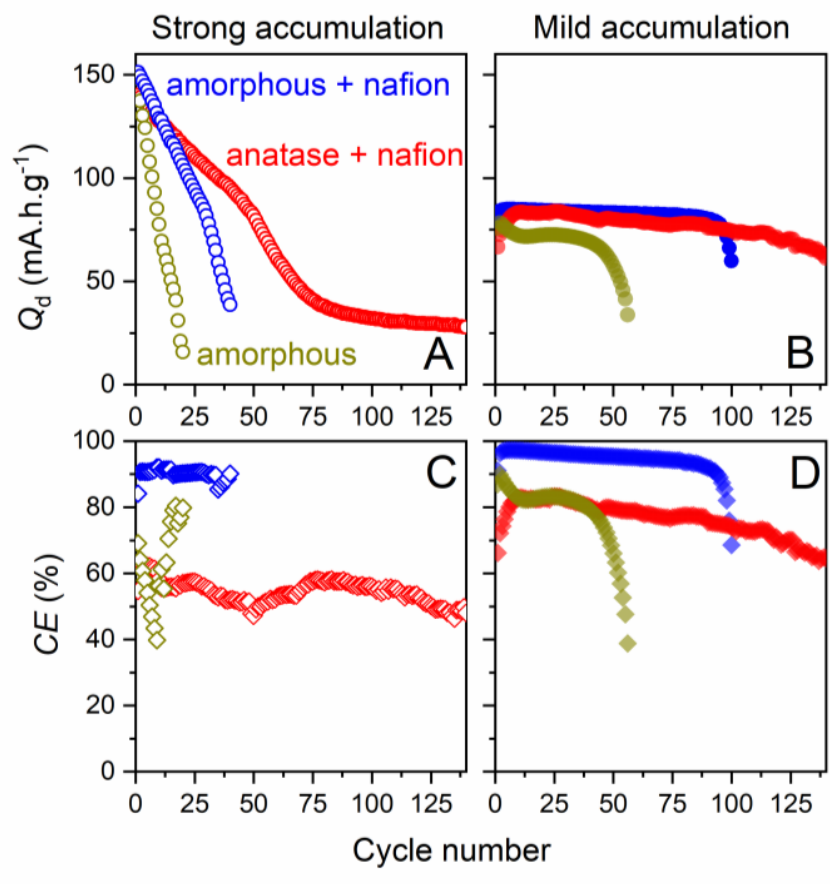

Figure 5. (A,B) Discharge capacities, $Q_{\mathrm{d}}$, and (C,D) corresponding Coulombic efficiencies, $C E$, recovered from continuous galvanostatic cycling experiments conducted at either (blue) Nafion-coated amorphous and (red) Nafion-coated anatase GLAD-TiO ${ }_{2}$ electrodes, or at (dark yellow) bare amorphous $\mathrm{GLAD}^{-\mathrm{TiO}_{2}}$ electrodes, under (empty symbols) strong or (filled symbols) mild accumulation conditions (see text for details). The rate was fixed at $0.36 \mathrm{~mA} \cdot \mathrm{cm}^{-2}$ (equivalent to $1.4 \mathrm{~A} \cdot \mathrm{g}^{-1}$ or $9.5 \mathrm{C}$ ) and the electrolyte was a $1 \mathrm{M}$ acetate buffer at $\mathrm{pH}$ 5.0.

rates). In order to better understand these competitive reactions, an amorphous $\mathrm{TiO}_{2}$ electrode was continuously cycled in a $1 \mathrm{M}$ acetate buffer using a fixed charging rate (sufficiently high so as to avoid the HER contribution) but various discharging rates (Figure S9). The galvanostatic charge/discharge curves show that the $Q_{\mathrm{d}}$ (and $C E$ ) values decrease significantly as the discharge rate is decreased, which, on account of the absence of HER during charging, suggests the presence of a competitive non-faradaic reaction that leads to the spontaneous consumption of stored electrons and protons. This reaction, which also corresponds to a self-discharge process, can be described as follows:

$2 \mathrm{Ti}{ }^{\mathrm{III}} \mathrm{OOH} \stackrel{k_{\text {self }}}{\longrightarrow} 2 \mathrm{Ti}^{\mathrm{IV}} \mathrm{O}_{2}+\mathrm{H}_{2}$

with $k_{\text {self }}$, the rate constant characterizing this spontaneous self-discharge reaction. Therefore, increasing the rate allows for an improved charge storage performance at both electrodes because the two slow, competitive reactions that irreversibly produce $\mathrm{H}_{2}$ (i.e. the faradaic hydrogen evolution reaction during the charge and the non-faradaic selfdischarge of the reduced $\mathrm{TiO}_{2}$ phase during discharge) are bypassed. Finally, a discharge gravimetric capacity as high as $95 \mathrm{~mA} \cdot \mathrm{h} \cdot \mathrm{g}^{-1}$ (or $C E=95 \%$ ) was obtained at both electrodes using a rate adjusted to $11 \mathrm{~A} \cdot \mathrm{g}^{-1}$ (or $75 \mathrm{C}$ ). This corresponds to a remarkable rate performance, allowing the charge or discharge of a capacity close to $100 \mathrm{~mA} \cdot \mathrm{h} \cdot \mathrm{g}^{-1}$ in less than $30 \mathrm{~s}$. Such a rate performance is better than that recently reported 
with layered titanates $\left(33 \mathrm{~mA} \cdot \mathrm{h} \cdot \mathrm{g}^{-1}\right.$ at $\left.4.2 \mathrm{~A} \cdot \mathrm{g}^{-1}\right){ }^{24}$ It also definitely highlights the fast bulk proton insertion in $\mathrm{TiO}_{2}$ electrode materials, even when the electrode is composed of a non-layered structure.

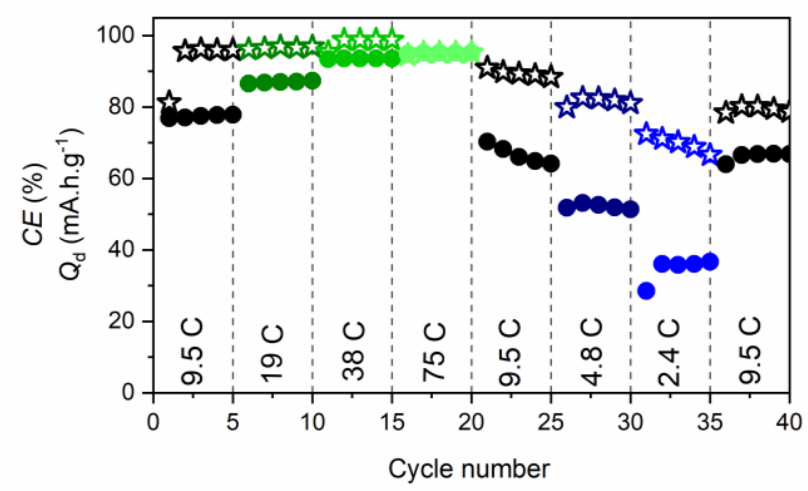

Figure 6. Discharge gravimetric capacities (or Coulombic efficiencies) obtained at Nafion-coated $(*)$ amorphous and $(\bullet)$ anatase GLAD- $\mathrm{TiO}_{2}$ electrodes during a continuous galvanostatic cycling experiment in which the charge was kept constant (i.e., $\left.100 \mathrm{~mA} \cdot \mathrm{h} \cdot \mathrm{g}^{-1}\right)$ and the discharge was controlled through a positive cut-off potential of o.o V vs. SCE. CE (\%) and $Q_{\mathrm{d}}\left(\mathrm{mA} \cdot \mathrm{h} \cdot \mathrm{g}^{-1}\right)$ may be plotted on the same axes because the charge accumulation was fixed at $100 \mathrm{~mA} \cdot \mathrm{h} \cdot \mathrm{g}$ '. Every 5 cycles, the charge/discharge rate was changed according to the following sequence: (black) $1.4 \mathrm{~A} \cdot \mathrm{g}^{-1}$, (dark green) $2.8 \mathrm{~A} \cdot \mathrm{g}^{-1}$, (green) $5.6 \mathrm{~A} \cdot \mathrm{g}^{-1}$, (light green) $11 \mathrm{~A} \cdot \mathrm{g}^{-1}$, (black) $1.4 \mathrm{~A} \cdot \mathrm{g}^{-1}$, (navy) $0.7 \mathrm{~A} \cdot \mathrm{g}^{-1}$, (blue) $0.35 \mathrm{~A} \cdot \mathrm{g}^{-1}$, and (black) $1.4 \mathrm{~A} \cdot \mathrm{g}^{-1}$.

\section{CONCLUSION}

In the present study, we explored the effect of crystallization on reversible proton insertion in nanostructured $\mathrm{TiO}_{2}$ electrodes prepared by glancing angle deposition. The morphological evolutions induced by the $400^{\circ} \mathrm{C}$ thermal annealing step were thoroughly analyzed, revealing a $\sim 2.5$ fold increase in the nanoparticle size and $\sim 3.5$-fold decrease in the electroactive surface area of the anatase electrode compared to the amorphous analog. Still, both electrodes allowed for a maximal reversible gravimetric capacity of $\sim 150$ $\mathrm{mA} \cdot \mathrm{h} \cdot \mathrm{g}^{-1}$ in a mild buffered aqueous electrolyte containing a Brønsted weak acid as the proton source. On the basis of a simple continuum $1 \mathrm{D}$ two-compartment model integrating a Frumkin isotherm, we succeeded in numerically simulating the CVs, revealing that the different shapes and positions of the reversible faradaic waves are mainly the consequence of the short-range interactions between inserted protons in $\mathrm{TiO}_{2}$. These phenomena strongly differed between the amorphous and crystalline phase of $\mathrm{TiO}_{2}$. We also demonstrated fast proton insertion kinetics, even for the anatase crystalline phase where $\mathrm{H}^{+}$diffusivity was definitely shown to outperform $\mathrm{Li}^{+}$diffusivity. These fast kinetics are consistent with the small size of the proton and its ability to induce a lower energy barrier to phase transformation. Overall, the above results demonstrate, in contrast to what was previously reported, that protons can massively and rapidly insert in a $3 \mathrm{D}$ crystalline metal oxide structure such as anatase, without requiring the assistance of structural ions and/or water in the lattice. We believe that this is a general principle that certainly extends to other metal oxide-based materials.

The present work has also revealed that the main issue for the exploitation of protons for charge storage in $\mathrm{TiO}_{2}$ is competitive HER, which strongly affects the Coulombic efficiently of the process as well as the long term cycling, especially at slow rates. We were able to show that these adverse effects could be significantly mitigated by adding a Nafion coating over the GLAD electrode surface, thereby allowing for an improved maximal charge storage capacity as well as better long-term cyclability. Further investigations are now required to establish the parameters governing the reactivity of $\mathrm{TiO}_{2}$ toward these side-reactions and thus to develop optimized electrode/electrolyte assemblies allowing us to fully benefit from the great charge storage performances related to the reversible $\mathrm{H}^{+}$insertion in mild aqueous electrolytes.

\section{ASSOCIATED CONTENT}

\section{Supporting Information}

Presentation of the modeling and simulation methodology, Supplementary Tables $\mathrm{S}_{1}$ and $\mathrm{S}_{2}$, Supplementary Figures $\mathrm{S}_{1}$ to S9 (PDF). The Supporting Information is available free of charge on the ACS Publications website.

\section{AUTHOR INFORMATION}

\section{Corresponding Authors}

* limoges@u-paris.fr, veronique.balland@u-paris.fr.

\section{Author Contributions}

All authors have given approval to the final version of the manuscript.

\section{Funding Sources}

DIM Respore is sincerely acknowledged for providing $\mathrm{PhD}$ funding to N.M.

\section{ACKNOWLEDGMENTS}

V.B. thank Stéphanie Lau-Truong (ITODYS, Université de Paris-CNRS) for assistance in Raman spectroscopy.

\section{REFERENCES}

(1) Larcher, D.; Tarascon, J. M. Towards Greener and More Sustainable Batteries for Electrical Energy Storage. Nat. $\begin{array}{lllll}\text { Chem. } & \text { 2015, } & 7 & \text { (1), } & 19-29 .\end{array}$ https://doi.org/10.1038/nchem.2085.

(2) Ji, X. A Paradigm of Storage Batteries. Energy Environ. Sci. 2019, 12 (11), 3203-3224. https://doi.org/10.1039/c9ee02356a.

(3) Demir-Cakan, R.; Palacin, M. R.; Croguennec, L. Rechargeable Aqueous Electrolyte Batteries: From Univalent to Multivalent Cation Chemistry. J. Mater. Chem. $\begin{array}{lllll}\text { A 2019, } & 7 & \text { (36), 20519-20539. }\end{array}$ https://doi.org/10.1039/c9tao4735b.

(4) Kim, Y.-S.; Kriegel, S.; Harris, K. D.; Costentin, C.; Limoges, B.; Balland, V. Evidencing Fast, Massive, and Reversible $\mathrm{H}^{+}$ Insertion in Nanostructured $\mathrm{TiO}_{2}$ Electrodes at Neutral PH. Where Do Protons Come From? J. Phys. Chem. C 2017, 121, 10325-10335. https://doi.org/10.1021/acs.jpcc.7bo2395.

(5) Kim, Y.-S.; Harris, K. D.; Limoges, B.; Balland, V. On the Unsuspected Role of Multivalent Metal Ions on the Charge Storage of a Metal Oxide Electrode in Mild Aqueous 
Electrolytes. Chem. Sci. 2019, 10 (38), $8752-8763$ https://doi.org/10.1039/c9sco2397f.

Huang, J.; Guo, Z.; Ma, Y.; Bin, D.; Wang, Y.; Xia, Y. Recent Progress of Rechargeable Batteries Using Mild Aqueous Electrolytes. Small Methods 2019, 3 (1), 1-20. https://doi.org/10.1002/smtd.201800272.

(7) Mateos, M.; Makivic, N.; Kim, Y.-S.; Limoges, B.; Balland, V. Accessing the Two-Electron Charge Storage Capacity of $\mathrm{MnO}_{2}$ in Mild Aqueous Electrolytes. Adv. Energy Mater. 2020, 10, 2000332. https://doi.org/10.1002/aenm.202000332.

(8) Li, Z.; Ganapathy, S.; Xu, Y.; Zhou, Z.; Sarilar, M.; Wagemaker, $M$. Mechanistic Insight into the Electrochemical Performance of $\mathrm{Zn} / \mathrm{VO}_{2}$ Batteries with an Aqueous $\mathrm{ZnSO}_{4}$ Electrolyte. Adv. Energy Mater. 2019, 1900237, 1-10. https://doi.org/10.1002/aenm.201900237.

(9) Zhao, Q.; Liu, L.; Yin, J.; Zheng, J.; Zhang, D.; Chen, J.; Archer, L. Proton Intercalation/de-Intercalation Dynamics in Vanadium Oxides for Aqueous Aluminum Electrochemical Cells. Angew. Chemie Int. Ed. 2020, 59, 1-6. https://doi.org/10.1002/anie.201912634.

(10) Mateos, M.; Harris, K. D.; Limoges, B.; Balland, V. Nanostructured Electrode Enabling Fast and Fully Reversible $\mathrm{MnO}_{2}$-to- $\mathrm{Mn}^{2+}$ Conversion in Mild Buffered Aqueous Electrolytes. ACS Appl. Energy Mater. 2020, 3, 7610-7618. https://doi.org/10.1021/acsaem.oc01039.

(11) Motupolly, S.; Streinz, C. C.; Weidner, J. W. Proton Diffusion in Nickel Hydroxide Films Measurement of the Diffusion Coefficient as a Function of State of Charge. J. Electrochem. Soc. 1995, 142 (5), 1401-1408. https://doi.org/10.1149/1.2048589.

(12) Xu, Y.; Wu, X.; Ji, X. The Renaissance of Proton Batteries. 2021, 2000113, 1-16. https://doi.org/10.1002/sstr.202000113.

(13) Mitchell, J. B.; Lo, W. C.; Genc, A.; Lebeau, J.; Augustyn, V. Transition from Battery to Pseudocapacitor Behavior via Structural Water in Tungsten Oxide. Chem. Mater. 2017, 29 (9),

3928-3937.

https://doi.org/10.1021/acs.chemmater.6bo5485.

(14) Mitchell, J. B.; Geise, N. R.; Paterson, A. R.; Osti, N. C.; Sun, Y.; Fleischmann, S.; Zhang, R.; Madsen, L. A.; Toney, M. F.; Jiang, D.; Kolesnikov, A. I.; Mamontov, E.; Augustyn, V. Confined Interlayer Water Promotes Structural Stability for High-Rate Electrochemical Proton Intercalation in Tungsten Oxide Hydrates. ACS Energy Lett. 2019, 4, 28052812. https://doi.org/10.1021/acsenergylett.9bo204o.

(15) Jiang, H.; Hong, J. J.; Wu, X.; Surta, T. W.; Qi, Y.; Dong, S.; Li, Z.; Leonard, D. P.; Holoubek, J. J.; Wong, J. C.; Razink, J. J.; Zhang, X.; Ji, X. Insights on the Proton Insertion Mechanism in the Electrode of Hexagonal Tungsten Oxide Hydrate. J. Am. Chem. Soc. 2018, 140 (37), 11556-11559. https://doi.org/10.1021/jacs.8bo3959.

(16) Wang, R.; Sun, Y.; Brady, A.; Fleischmann, S.; Eldred, T. B.; Gao, W.; Wang, H.; Jiang, D.; Augustyn, V. Fast Proton Insertion in Layered $\mathrm{H}_{2} \mathrm{~W}_{2} \mathrm{O}_{7}$ via Selective Etching of an Aurivillius Phase. Adv. Energy Mater. 2020, 2003335, 1-9. https://doi.org/10.1002/aenm.202003335.

(17) Wang, X.; Xie, Y.; Tang, K.; Wang, C.; Yan, C. Redox Chemistry of Molybdenum Trioxide for Ultrafast Hydrogen-Ion Storage. Angew. Chemie - Int. Ed. 2018, 57 (36), 11569-11573. https://doi.org/10.1002/anie.201803664.

(18) Guo, H.; Goonetilleke, D.; Sharma, N.; Ren, W.; Su, Z.; Rawal, A.; Zhao, C. Two-Phase Electrochemical Proton Transport and Storage in a-MoO 3 for Proton Batteries. Cell Reports Phys. Sci. 2020, 1, 100225. https://doi.org/10.1016/j.xcrp.2020.100225.

(19) Su, Z.; Ren, W.; Guo, H.; Peng, X.; Chen, X.; Zhao, C. Ultrahigh Areal Capacity Hydrogen-Ion Batteries with $\mathrm{MoO}_{3}$ Loading Over $90 \mathrm{Mg} \mathrm{Cm}^{-2}$. Adv. Funct. Mater. 2020, 2005477, 1-8. https://doi.org/10.1002/adfm.202005477.

(20) Perez, A. J.; Beer, R.; Lin, Z.; Salager, E.; Taberna, P.-L.;
Abakumov, A. M.; Simon, P.; Tarascon, J. M. Proton Ion Exchange Reaction in $\mathrm{Li}_{3} \mathrm{IrO}_{4}$ : A Way to New $\mathrm{H}_{3+\mathrm{x}} \mathrm{IrO}_{4}$ Phases Electrochemically Active in Both Aqueous and Nonaqueous Electrolytes. Adv. Energy Matrials 2018, 1702855. https://doi.org/10.1002/aenm.201702855.

Lemaire, P.; Sel, O.; Alves Dalla Corte, D.; Iadecola, A.; Perrot, H.; Tarascon, J.-M. Elucidating the Origin of the Electrochemical Capacity in a Proton-Based Battery $\mathrm{H}_{\mathrm{x}} \mathrm{IrO}_{4}$ via Advanced Electrogravimetry. ACS Appl. Mater. Interfaces 2020, 12 (4), 4510-4519. https://doi.org/10.1021/acsami.9b19349.

Zhang, L.; Miao, L.; Zhang, B.; Wang, J.; Liu, J.; Tan, Q.; Wan, H.; Jiang, J. A Durable $\mathrm{VO}_{2}(\mathrm{M}) / \mathrm{Zn}$ Battery with Ultrahigh Rate Capability Enabled by Pseudocapacitive Proton. J. Mater. Chem. A 2020, 2 (8), 1731-1740. https://doi.org/10.1039/c9ta11031c.

Fleischmann, S.; Sun, Y.; Osti, N. C.; Wang, R.; Mamontov, E.; Jiang, D.; Augustyn, V. Interlayer Separation in Hydrogen Titanates Enables Electrochemical Proton Intercalation. J. Mater. Chem. A 2019. https://doi.org/10.1039/c9ta11098d.

Kang, S.; Singh, A.; Reeves, K. G.; Badot, J.; Durand-vidal, S.; Legein, C.; Body, M.; Dubrunfaut, O.; Borkiewicz, O. J.; Laberty-robert, C.; Dambournet, D. Hydronium Ions Stabilized in a Titanate-Layered Structure with High Ionic Conductivity: Application to Aqueous Proton Batteries. Chem. Mater. 2020, $32 \quad$ (21), 9458-9469. https://doi.org/10.1021/acs.chemmater.oc03658.

Song, T.; Paik, U. $\mathrm{TiO}_{2}$ as an Active or Supplemental Material for Lithium Batteries. J. Mater. Chem. A 2016, 4 (1), 14-31. https://doi.org/10.1039/c5tao6888f.

Dylla, A. G.; Henkelman, G.; Stevenson, K. J. Lithium Insertion in Nanostructured $\mathrm{TiO}_{2}$ (B) Architectures. Acc. Chem. Res. 2013, 46 (5), 1104-1112. https://doi.org/10.1021/ar30o176y.

Sudant, G.; Baudrin, E.; Larcher, D.; Tarascon, J. Electrochemical Lithium Reactivity with Nanotextured Anatase-Type $\mathrm{TiO}_{2}$. J. Mater. Chem. 2005, No. 1, 1263-1269. https://doi.org/10.1039/b416176a.

Wagemaker, M.; Borghols, W. J. H.; Mulder, F. M. Large Impact of Particle Size on Insertion Reactions. A Case for Anatase $\mathrm{Li}_{\mathrm{x}} \mathrm{TiO}_{2}$. J. Am. Chem. Soc. 2007, 11 (8), 4323-4327.

Gentili, V.; Brutti, S.; Hardwick, L. J.; Armstrong, A. R.; Panero, S.; Bruce, P. G. Lithium Insertion into Anatase Nanotubes. Chem. Mater. 2012, 24, 4468-4476.

Lemon, B. I.; Hupp, J. T. Photochemical Quartz Crystal Microbalance Study of the Nanocrystalline Titanium Dioxide Semiconductor Electrode/Water Interface: Simultaneous Photoaccumulation of Electrons and Protons. J. Phys. Chem. 1996, 100 (96), 14578-14580. https://doi.org/10.1021/jp961749s.

Lyon, L. A.; Hupp, J. T. Energetics of the Nanocrystalline Titanium Dioxide/Aqueous Solution Interface: Approximate Conduction Band Edge Variations between $\mathrm{H}_{\mathrm{o}}$ $=-10$ and $H_{-}=+26$. J. Phys. Chem. $B$ 1999, 103 (22), 46234628. https://doi.org/10.1021/jp9908404.

Pelouchova, H.; Janda, P.; Weber, J.; Kavan, L. Charge Transfer Reductive Doping of Single Crystal $\mathrm{TiO}_{2}$ Anatase. J. Electroanal. Chem. 2004, 566 (1), 73-83. https://doi.org/10.1016/j.jelechem.2003.11.o13.

Ghicov, A.; Tsuchiya, H.; Hahn, R.; MacAk, J. M.; Munoz, A. G.; Schmuki, P. $\mathrm{TiO}_{2}$ Nanotubes: $\mathrm{H}^{+}$Insertion and Strong Electrochromic Effects. Electrochem. commun. 2oo6, 8 (4), 528-532. https://doi.org/10.1016/j.elecom.2006.01.015.

Krause, K. M.; Taschuk, M. T.; Harris, K. D.; Rider, D. A.; Wakefield, N. G.; Sit, J. C.; Buriak, J. M.; Thommes, M.; Brett, M. J. Surface Area Characterization of Obliquely Deposited Metal Oxide Nanostructured Thin Films. Langmuir 2010, $26 \quad$ (6), 4368-4376. 
Garoz-ruiz, J.; Heras, A.; Palmero, S.; Colina, A. Development of a Novel Bidimensional Spectroelectrochemistry Cell Using Transfer Single-Walled Carbon Nanotubes Films as Optically Transparent Electrodes. Anal Chem 2015, 87, 6233-6239. https://doi.org/10.1021/acs.analchem.5boog23.

(36) Ohsaka, T.; Izumi, F.; Fujiki, Y. Raman Spectrum of Anatase, TiO2. J. Raman Spectrosc. 1978, 7 (6), 321-324.

(37) Xue, X.; Ji, W.; Mao, Z.; Mao, H.; Wang, Y.; Wang, X.; Ruan, W.; Zhao, B.; Lombardi, J. R. Raman Investigation of Nanosized $\mathrm{TiO}_{2}$ : Effect of Crystallite Size and Quantum Confinement. J. Phys. Chem. C 2012, 116, 8792-8797. https://doi.org/10.1021/jp2122196.

(38) Furukawa, H.; Hibino, M.; Honma, I. Electrochemical Properties of Nanostructured Amorphous, Sol-GelSynthesized $\mathrm{TiO}_{2} /$ Acetylene Black Composite Electrodes. J. $\begin{array}{lllll}\text { Electrochem. Soc. 2004, } & 151 \quad \text { (4), } & 2-7 .\end{array}$ https://doi.org/10.1149/1.1649747.

(39) Costentin, C.; Savéant, J.-M. Electrochemical Capacitive Charging in Porous Materials. Discriminating between Ohmic Potential Drop and Counterion Diffusion. ACS Appl. Energy Mater. 2019, 2 (7), 4981-4986. https://doi.org/10.1021/acsaem.9boo663.

(40) Lindström, H.; Södergren, S.; Solbrand, A.; Rensmo, H.; Hjelm, J.; Hagfeldt, A.; Lindquist, S.-E. Li ${ }^{+}$Ion Insertion in $\mathrm{TiO}_{2}$ (Anatase). 1. Chronoamperometry on CVD Films and Nanoporous Films. J. Phys. Chem. B 1997, 101 (39), 77107716. https://doi.org/10.1021/jp970489r.

(41) Levi, M. D.; Aurbach, D. Frumkin Intercalation Isotherm - a Tool for the Description of Lithium Insertion into Host Materials : A Review. Electrochim. Acta 1999, 45, 167-185.

(42) Nikitina, V. A.; Vassiliev, S. Y.; Stevenson, K. J. Metal-Ion Coupled Electron Transfer Kinetics in Intercalation-Based Transition Metal Oxides. Adv. Energy Mater. 2020, 1903933, 1-28. https://doi.org/10.1002/aenm.201903933.

(43) Lindström, H.; Södergren, S.; Solbrand, A.; Rensmo, H.; Hjelm, J.; Hagfeldt, A.; Lindquist, S.-E. $\mathrm{Li}^{+}$Ion Insertion in $\mathrm{TiO}_{2}$ (Anatase). 2. Voltammetry on Nanoporous Films. J. Phys. Chem. B 1997, 101 (39), 7717-7722. https://doi.org/10.1021/jp97049oq.

(44) Moitzheim, S.; De Gendt, S.; Vereecken, P. M. Investigation of the Li-Ion Insertion Mechanism for Amorphous and Anatase $\mathrm{TiO}_{2}$ Thin-Films. J. Electrochem. Soc. 2019, 166 (2), A1-A9. https://doi.org/10.1149/2.1091816jes.

(45) Deng, C.; Lau, L.; Ma, C.; Skinner, P.; Liu, Y.; Xu, W.; Zhou, H.; Zhang, X.; Wu, D.; Yin, Y.; Ren, Y.; Perez, J.; Jaramillo, D.; Barnes, P.; Hou, D.; Dahl, M.; Williford, B.; Zheng, C.; Xiong, H. (Claire). A Mechanistic Study of Mesoporous $\mathrm{TiO}_{2}$ Nanoparticle Negative Electrode Materials with Varying Crystallinity for Lithium Ion Batteries. J. Mater. Chem. A 2020, 8, 3333-3343. https://doi.org/10.1039/C9TA12499C.

(46) Van De Krol, R.; Goossens, A.; Schoonman, J. Spatial Extent of Lithium Intercalation in Anatase $\mathrm{TiO}_{2}$. J. Phys. Chem. B 1999, 103, 7151-7159. https://doi.org/10.1021/jp9909964.

(47) Wagemaker, M.; van de Krol, R.; Kentgens, A. P.; van Well, A. A.; Mulder, F. M. Two Phase Morphology Limits Lithium Diffusion in $\mathrm{TiO}_{2}$ (Anatase): A ${ }^{7} \mathrm{Li}$ MAS NMR Study. J. Am. Chem. Soc. 2001, 123 (46), 11454-11461. https://doi.org/10.1021/jao161148.

(48) Ortiz, G. F.; Hanzu, I.; Djenizian, T.; Lavela, P.; Tirado, J. L.; Knauth, P. Alternative Li-Ion Battery Electrode Based on Self-Organized Titania Nanotubes. Chem. Mater. 20o9, 21 (1), 63-67.

(49) Lin, Y. M.; Abel, P. R.; Flaherty, D. W.; Wu, J.; Stevenson, K.
J.; Heller, A.; Mullins, C. B. Morphology Dependence of the Lithium Storage Capability and Rate Performance of Amorphous $\mathrm{TiO}_{2}$ Electrodes. J. Phys. Chem. C 2011, 115 (5), 2585-2591. https://doi.org/10.1021/jp110474y.

(50) Huang, S.; Zhang, L.; Lu, X.; Liu, L.; Liu, L.; Sun, X.; Yin, Y.; Oswald, S.; Zou, Z.; Ding, F.; Schmidt, O. G. Tunable Pseudocapacitance in $3 \mathrm{D} \mathrm{TiO}_{2-\delta}$ Nanomembranes Enabling Superior Lithium Storage Performance. ACS Nano 2017, 11 (1), 821-83o. https://doi.org/10.1021/acsnano.6bo7274.

(51) Jiang, Y.; Hall, C.; Song, N.; Lau, D.; Burr, P. A.; Patterson, R.; Wang, D.; Ouyang, Z.; Lennon, A. Evidence for Fast Lithium-Ion Diffusion and Charge-Transfer Reactions in Amorphous $\mathrm{TiO}_{x}$ Nanotubes: Insights for High-Rate Electrochemical Energy Storage. ACS Appl. Mater. Interfaces 2018, 10, 42513-42523. https://doi.org/10.1021/acsami.8b16994.

(52) Auer, A.; Steiner, D.; Portenkirchner, E.; Kunze-Liebhäuser J. Nonequilibrium Phase Transitions in Amorphous and Anatase $\mathrm{TiO}_{2}$ Nanotubes. ACS Appl. Energy Mater. 2018, 1 (5), 1924-1929. https://doi.org/10.1021/acsaem.7boo319.

(53) Ye, J.; Shea, P.; Baumgaertel, A. C.; Bonev, S. A.; Biener, M. M.; Bagge-Hansen, M.; Wang, Y. M.; Biener, J.; Wood, B. C. Amorphization as a Pathway to Fast Charging Kinetics in Atomic Layer Deposition-Derived Titania Films for Lithium Ion Batteries. Chem. Mater. 2018, 30, 8871-8882. https://doi.org/10.1021/acs.chemmater.8bo4002.

(54) Fang, H. T.; Liu, M.; Wang, D. W.; Sun, T.; Guan, D. S.; Li, F.; Zhou, J.; Sham, T. K.; Cheng, H. M. Comparison of the Rate Capability of Nanostructured Amorphous and Anatase $\mathrm{TiO}_{2}$ for Lithium Insertion Using Anodic $\mathrm{TiO}_{2}$ Nanotube Arrays. Nanotechnology 2009, 20, 225701. https://doi.org/10.1088/o957-4484/20/22/225701.

(55) Koudriachova, M. V; Leeuw, S. W. De; Harrison, N. M. Orthorhombic Distortion on Li Intercalation in Anatase. Phys. Rev. B 2004, 69, 054106. https://doi.org/10.1103/PhysRevB.69.054106.

(56) Kim, Y. S.; Balland, V.; Limoges, B.; Costentin, C. Cyclic Voltammetry Modeling of Proton Transport Effects on Redox Charge Storage in Conductive Materials: Application to a $\mathrm{TiO}_{2}$ Mesoporous Film. Phys. Chem. Chem. Phys. 2017, 19 (27), 17944-17951. https://doi.org/10.1039/C7CPo281oE.

(57) Belak, A. A.; Wang, Y.; Van der Ven, A. Kinetics of Anatase Electrodes: The Role of Ordering, Anisotropy, and Shape Memory Effects. Chem. Mater. 2012, 24, 2894-2898.

(58) Baddour-Hadjean, R.; Bach, S.; Smirnov, M.; Pereira-Ramos, J.-P. Raman Investigation of the Structural Changes in Anatase $\mathrm{Li}_{x} \mathrm{TiO}_{2}$ upon Electrochemical Lithium Insertion. Joural Raman Spectrosc. 2004, 35, 577-585. https://doi.org/10.1002/jrs.1200.

(59) Hardwick, L. J.; Holzapfel, M.; Nov, P.; Baudrin, E. Electrochemical Lithium Insertion into Anatase-Type $\mathrm{TiO}_{2}$ : An in Situ Raman Microscopy Investigation. Electrochim. Acta 2007, 52, 5357-5367. https://doi.org/10.1016/j.electacta.2007.02.050.

(6o) Laskova, B.; Frank, O.; Zukalova, M.; Bousa, M.; Dracinsky, M.; Kavan, L. Lithium Insertion into Titanium Dioxide (Anatase): A Raman Study with ${ }^{16 / 18} \mathrm{O}$ and ${ }^{6 / 7} \mathrm{Li}$ Isotope Labeling. Chem. Mater. 2013, 25, 3710-3717. https://doi.org/10.1021/cm402056j.

(61) Eyövge, C.; Öztürk, T. Nafion Coated $\mathrm{Mg}_{50} \mathrm{Ni}_{5_{0}}$ and $(\mathrm{La}, \mathrm{Mg})_{2} \mathrm{Ni}_{7}$ Negative Electrodes for NiMH Batteries. J. Electrochem. Soc. 2018, 165 (10), A2203-A2208. https://doi.org/10.1149/2.0681810jes. 